\title{
Categorical Abstract Algebraic Logic: Equivalential $\pi$-Institutions
}

\author{
George Voutsadakis \\ School of Mathematics and Computer Science, Lake Superior \\ State University, Sault Sainte Marie, MI 49783, USA \\ gvoutsad@lssu.edu \\ Received by Greg Restall \\ Published August 4, 2008 \\ http://www.philosophy.unimelb.edu.au/ajl/2008 \\ (C) 2008 George Voutsadakis
}

\begin{abstract}
The theory of equivalential deductive systems, as introduced by Prucnal and Wroński and further developed by Czelakowski, is abstracted to cover the case of logical systems formalized as $\pi$-institutions. More precisely, the notion of an $\mathrm{N}$-equivalence system for a given $\pi$-institution is introduced. A characterization theorem for $\mathrm{N}$-equivalence systems, previously proven for $\mathrm{N}$-parameterized equivalence systems, is revisited and a "transfer theorem" for $\mathrm{N}$-equivalence systems is proven. For a $\pi$-institution $\mathcal{J}$ having an $\mathrm{N}$-equivalence system, the maximum such system is singled out and, then, an analog of Herrmann's Test, characterizing those $\mathrm{N}$-protoalgebraic $\pi$-institutions having an $\mathrm{N}$-equivalence system, is formulated. Finally, some of the rudiments of matrix theory are revisited in the context of $\pi$-institutions, as they relate to the existence of $\mathrm{N}$-equivalence systems.
\end{abstract}

\section{INTRODUCTION}

One of the major accomplishments of the modern theory of abstract algebraic logic, as developed by Czelakowski, Blok and Pigozzi and Font and Jansana among others, has been the classification of sentential logics in different classes of an abstract algebraic hierarchy, whose various steps reflect the amenability of the logic to algebraic study techniques. The logics at the bottom steps of the hierarchy are loosely connected to their algebraic counterparts whereas those in higher steps have stronger connections. The stronger the connections, the more the conclusions that may be drawn on metalogical properties possessed

\footnotetext{
o Keywords: algebraic logic, equivalent deductive systems, algebraizable logics, lattice of theories, Leibniz operator, protoalgebraic logics, equivalential logics, institutions, equivalent institutions, algebraizable institutions, protoalgebraic $\pi$-institutions, Leibniz congruence systems, parameterized equivalence systems.

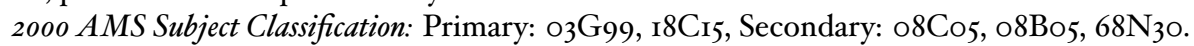


by the logics by studying corresponding algebraic properties of classes of algebras forming their algebraic counterparts.

In this abstract algebraic hierarchy, known also as the Leibniz hierarchy, the class of equivalential logics [I8, 6] lies between the classes of protoalgebraic logics [2] and algebraizable logics [3, 14, I5, I6 ; algebraizable logics are, in fact, exactly those logics that are at the same time equivalential and weakly algebraizable:

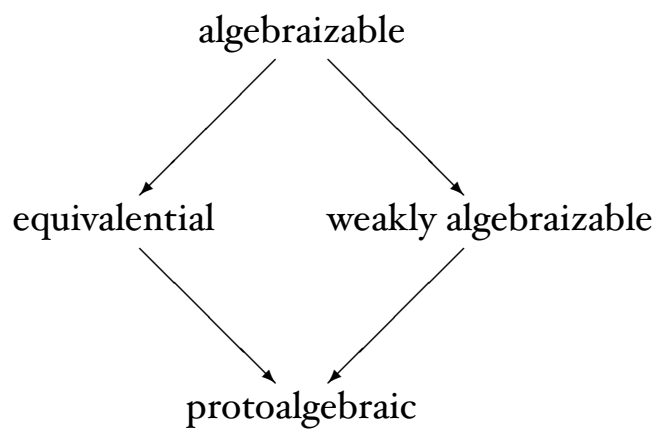

Equivalential logics were first introduced by Prucnal and Wroński [I8] and they have the honor to be the first class of logics in the abstract algebraic hierarchy to be singled out during the early days of the history of abstract algebraic logic (see [II]). They were later studied in great detail by Czelakowski in [6.

A (sentential) logic or deductive system $\mathcal{S}$ is a pair $\mathcal{S}=\langle\mathcal{L}, \mathrm{C}\rangle$, where $\mathcal{L}$ is a set of connectives or operation symbols (depending on whether the point of view is logical or algebraic, respectively) and $\mathrm{C}: \mathcal{P}\left(\mathrm{Fm}_{\mathcal{L}}(\mathrm{V})\right) \rightarrow \mathcal{P}\left(\mathrm{Fm}_{\mathcal{L}}(\mathrm{V})\right)$ is a finitary and structural closure operator on the set $\mathrm{Fm}_{\mathcal{L}}(\mathrm{V})$ of $\mathcal{L}$-formulas built out of a fixed, denumerable set of variables $V$. According to the original definition, a logic $\mathcal{S}=\langle\mathcal{L}, C\rangle$ is said to be equivalential if there exists a set $E(p, q)$ of $\mathcal{L}$-formulas in two variables $p, q$, such that, for all $\phi, \chi, \psi \in \operatorname{Fm}_{\mathcal{L}}(V)$,

I. $\mathrm{E}(\phi, \phi) \subseteq \mathrm{C}(\emptyset)$,

2. $\mathrm{E}(\psi, \phi) \subseteq \mathrm{C}(\mathrm{E}(\phi, \psi))$,

3. $E(\phi, \chi) \subseteq C(E(\phi, \psi) \cup E(\psi, \chi))$,

4. $E(\lambda(\vec{\phi}), \lambda(\vec{\psi})) \subseteq C\left(\bigcup_{i<n} E\left(\phi_{i}, \psi_{i}\right)\right)$, for all $\lambda \in \mathcal{L}, n$-ary, and all $\vec{\phi}, \vec{\psi} \in \operatorname{Fm}_{\mathcal{L}}(V)^{n}$,

5. $\psi \in C(E(\phi, \psi) \cup\{\phi\})$.

Later, it was shown that Conditions I,4 and 5, above, suffice and a set $E(p, q)$ satisfying these three conditions is called an equivalence for $\mathcal{S}$. It may be shown that $E(p, q)$ is an equivalence for $\mathcal{S}$ if and only if, for every $\mathcal{S}$-matrix $\mathfrak{A}=\langle\mathrm{A}, \mathrm{F}\rangle$ and all $\mathrm{a}, \mathrm{b} \in \mathrm{A}$,

$$
\langle a, b\rangle \in \Omega_{\mathrm{A}}(\mathrm{F}) \quad \text { iff } \quad E(a, b) \subseteq F,
$$


where, by $\Omega_{A}(F)$ is denoted the Leibniz congruence of $F$ on $A$, i.e., the largest congruence on the algebra $A$ that is compatible with the filter $F$.

Several characterizations exist of equivalential logics. According to one (Theorem 3.2.I of [7]]), a logic $\mathcal{S}$ is equivalential iff it is protoalgebraic and the class $\operatorname{Mod}(\mathcal{S})$ of its matrix models has the $\Omega$-extension property, i.e., for every $\mathcal{S}$-matrix $\mathfrak{M}$ and every submatrix $\mathfrak{N} \leqslant \mathfrak{M}$, the Leibniz congruence $\Omega(\mathfrak{N})$ is the restriction of the Leibniz congruence $\Omega(\mathfrak{M})$ to $\mathfrak{N}$. A second one (Theorem 3.2.8 of [7] $)$ states that $\mathcal{S}$ is equivalential iff the class $\operatorname{Mod}^{*}(\mathcal{S})$ of its reduced matrix models is closed under the formation of $\sigma$-filtered subdirect products. Yet another (Theorem 3.3.4 of [7] $]$ ), perhaps the best known, states that $\mathcal{S}$ is equivalential iff the Leibniz operator is monotone and commutes with inverse substitutions on the theories of $\mathcal{S}$. Finally, $\mathcal{S}$ is equivalential iff the Leibniz operator is $\sigma$-continuous on the lattice of $\mathcal{S}$-filters on any $\mathcal{L}$-algebra (Theorem 3.3.6 of $[7]$ ). Corresponding results exist also for characterizing the class of finitely equivalential logics, i.e., those logics that are finitary and possess a finite equivalence E. Czelakowski in [7] presents a variety of examples of equivalential logics from the realm of modal logic, tense logic and dynamic logic. The reader is encouraged to consult these examples and to compare the equivalential with the other classes of logics in the abstract algebraic hierarchy.

The classification of the various logical systems into the classes of the Leibniz hierarchy was originally accomplished only for sentential logics. Logics with multiple-signatures and quantifiers, such as multi-signature equational and first-order logic, can be handled in this context but in a rather inelegant, clumsy way. Their handling presupposes first their transformation into sentential logics via an ad-hoc process. The original theory has also the limitation that it cannot handle directly logical systems whose syntax is not string-based. These shortcomings motivated an effort to develop an analog of the theory that deals with the algebraization of $\pi$-institutions instead of sentential logics. $\pi$-institutions are more general structures that encompass sentential logics as well as a wide variety of logics with multiple signatures and quantifiers and also other logical systems with more abstract syntactic apparatuses. See [19,20] for more details on the limitations of the sentential logic framework that led to this more general institutional-based approach and also for examples of algebraization processes using this newer, more powerful machinery.

Recently, the operator approach to abstract algebraic logic, that led to the classification of sentential logics in the various classes of the abstract algebraic hierarchy, has been carried over to the context of $\pi$-institutions in the series of papers [2I]-[32], via the introduction of a categorical Tarski operator [2I], generalizing the Tarski operator of Font and Jansana [IO]. Based on this work, a categorical Leibniz operator was introduced in $[27$, and the class of $\mathrm{N}$-protoalgebraic $\pi$-institutions was formed and studied in some detail. [28 complements and builds further on the work of [27]. Moreover, in [3I] the class of $\mathrm{N}$-weakly algebraizable $\pi$-institutions was defined, in the same framework, this time taking after the definition of the class of weakly algebraizable 
sentential logics by Czelakowski and Jansana [8]. Looking at the diagram of the lowest classes of the abstract algebraic hierarchy, presented above, the only class an analog of which has not yet been studied in the categorical framework is the class of equivalential logics. The goal of the present work is to begin that study.

As is the case with sentential logics, the key notion in the study of equivalentiality is that of an equivalence system. N-equivalence systems are introduced and studied in Section 3. It should be mentioned that they form a special case of the $\mathrm{N}$-parameterized equivalence systems of [28], being $\mathrm{N}$ parameterized but without parameters. Thus, some of the results presented in Section 3 are special cases of results presented in 28 and, as a consequence, are given without proofs.

In Section 4, the study of $\mathrm{N}$-equivalence systems is continued, but the results presented have a close relationship with applications of the theory of the $N$-Leibniz operator to $\pi$-institutions. A feature result here is Theorem I3, which characterizes the largest $\mathrm{N}$-equivalence system of a $\pi$-institution that possesses one. Another interesting result, Theorem I5. is an analog of Herrmann's Test ([6], see also Theorem 3.3.3 of [7] ), that characterizes equivalential sentential logics inside the wider class of protoalgebraic logics. In the last two main results of Section 4 , it is shown, roughly speaking, that having an $\mathrm{N}$-equivalence system implies monotonicity and "commutativity with inverse translations" of the N-Leibniz operator and also its $\mu$-continuity under suitable cardinality restrictions.

Unfortunately, as was the case with many of the results pertaining to $\mathrm{N}$ protoalgebraicity and $\mathrm{N}$-weak algebraizability, many of the characterization results from the sentential framework seem to only yield necessary but not sufficient conditions in the $\pi$-institution context. This leads, in Section 4, to the introduction of two classes of $\mathrm{N}$-equivalential $\pi$-institutions. The, socalled, syntactically $\mathrm{N}$-equivalential, containing those $\pi$-institutions having an $\mathrm{N}$-equivalence system, and the semantically $\mathrm{N}$-equivalential, characterized by monotonicity and commutativity with inverse translations of the N-Leibniz operator on the lattice of theory families of the $\pi$-institution.

In the last section, some of the rudiments of the theory of logical matrices are revisited in the context of $\pi$-institutions. The matrices adapted in this context are called $\mathrm{N}$-matrix systems. Some of the results presented in Section 3 are recast in terms of $\mathrm{N}$-matrix systems.

For all unexplained categorical terminology and notation the reader is referred to any of [I, 5, [7]. For the definitions pertaining to institutions see [12, [3], whereas $\pi$-institutions were introduced in [9]. For background on the theory of abstract algebraic logic and a more detailed discussion of the classes of the abstract algebraic hierarchy, some of which were mentioned in this introduction, the reader is referred to the review article [II], the monograph [IO] and Czelakowski's book [7]. 


\section{A FEW PRELIMINARIES}

Before proceeding with the main developments, we remind the reader of two of the basic notions that form the framework in which our studies will take place.

Recall that a $\pi$-institution [9] is a triple $\mathcal{J}=\langle$ Sign, SEN, C $\rangle$, where

(i) Sign is a category, whose objects are called signatures.

(ii) SEN : Sign $\rightarrow$ Set is a set-valued functor from the category Sign of signatures, called the sentence functor and giving, for each signature $\Sigma$, a set whose elements are called sentences over that signature $\Sigma$ or $\Sigma$ sentences.

(iii) $\mathrm{C}_{\Sigma}: \mathcal{P}(\operatorname{SEN}(\Sigma)) \rightarrow \mathcal{P}(\operatorname{SEN}(\Sigma))$, for each $\Sigma \in|\operatorname{Sign}|$, is a mapping, called $\Sigma$-closure, such that

(a) $A \subseteq C_{\Sigma}(A)$, for all $\Sigma \in|\operatorname{Sign}|, A \subseteq \operatorname{SEN}(\Sigma)$,

(b) $C_{\Sigma}\left(C_{\Sigma}(A)\right)=C_{\Sigma}(A)$, for all $\Sigma \in|\operatorname{Sign}|, A \subseteq \operatorname{SEN}(\Sigma)$,

(c) $\mathrm{C}_{\Sigma}(\mathrm{A}) \subseteq \mathrm{C}_{\Sigma}$ (B), for all $\Sigma \in|\operatorname{Sign}|, A \subseteq \mathrm{B} \subseteq \operatorname{SEN}(\Sigma)$,

(d) $\operatorname{SEN}(f)\left(C_{\Sigma_{1}}(A)\right) \subseteq C_{\Sigma_{2}}(\operatorname{SEN}(f)(A))$, for all $\Sigma_{1}, \Sigma_{2} \in|\operatorname{Sign}|$, $f \in \operatorname{Sign}\left(\Sigma_{1}, \Sigma_{2}\right), A \subseteq \operatorname{SEN}\left(\Sigma_{1}\right)$.

Recall also from $[27$, (this is a corrected version of the original definition given in [2I]) that, given a sentence functor SEN : Sign $\rightarrow$ Set, the clone of all natural transformations on SEN is defined to be the locally small category with collection of objects $\left\{\operatorname{SEN}^{\alpha}: \alpha\right.$ an ordinal $\}$ and collection of morphisms $\tau: \operatorname{SEN}^{\alpha} \rightarrow \operatorname{SEN}^{\beta} \beta$-sequences of natural transformations $\tau_{i}$ : $\mathrm{SEN}^{\alpha} \rightarrow$ SEN. Composition

$$
\operatorname{SEN}^{\alpha} \stackrel{\left\langle\tau_{i}: i<\beta\right\rangle}{\longrightarrow} \operatorname{SEN}^{\beta} \stackrel{\left\langle\sigma_{j}: j<\gamma\right\rangle}{\longrightarrow} \operatorname{SEN}^{\gamma}
$$

is defined by

$$
\left\langle\sigma_{j}: j<\gamma\right\rangle \circ\left\langle\tau_{i}: i<\beta\right\rangle=\left\langle\sigma_{j}\left(\left\langle\tau_{i}: i<\beta\right\rangle\right): j<\gamma\right\rangle .
$$

A subcategory $\mathrm{N}$ of this category containing all objects of the form $\mathrm{SEN}^{\mathrm{k}}$ for $k<\omega$, and all projection morphisms $p^{k, i}: \mathrm{SEN}^{k} \rightarrow \operatorname{SEN}, i<k, k<\omega$, with $p_{\Sigma}^{k, i}: \operatorname{SEN}(\Sigma)^{k} \rightarrow \operatorname{SEN}(\Sigma)$ given by

$$
p_{\Sigma}^{k, i}(\vec{\phi})=\phi_{i}, \quad \text { for all } \quad \vec{\phi} \in \operatorname{SEN}(\Sigma)^{k}
$$

and such that, for every family $\left\{\tau_{i}: \operatorname{SEN}^{k} \rightarrow \operatorname{SEN}: i<l\right\}$ of natural transformations in $N$, the sequence $\left\langle\tau_{i}: i<l\right\rangle: \operatorname{SEN}^{k} \rightarrow \operatorname{SEN}^{l}$ is also in $N$, is referred to as a category of natural transformations on SEN. 
Given a functor SEN : Sign $\rightarrow$ Set, a collection $\theta=\left\{\theta_{\Sigma}\right\}_{\Sigma \in \mid \text { Sign } \mid}$, such that $\theta_{\Sigma}$ is an equivalence relation on $\operatorname{SEN}(\Sigma)$, for all $\Sigma \in|\operatorname{Sign}|$, is called an equivalence family on SEN. If, in addition, for all $\Sigma_{1}, \Sigma_{2} \in|\mathrm{Sign}|$, $f \in \operatorname{Sign}\left(\Sigma_{1}, \Sigma_{2}\right), \theta$ satisfies $\operatorname{SEN}(f)^{2}\left(\theta_{\Sigma_{1}}\right) \subseteq \theta_{\Sigma_{2}}$, then $\theta$ is said to be an equivalence system on SEN. If $N$ is a category of natural transformations on SEN and an equivalence system $\theta$ on SEN satisfies, for all $\sigma:$ SEN $^{n} \rightarrow$ SEN in $\mathrm{N}$, all $\Sigma \in|\mathrm{Sign}|$ and all $\phi_{0}, \psi_{0}, \ldots, \phi_{n-1}, \psi_{n-1} \in \operatorname{SEN}(\Sigma)$,

$$
\left\langle\phi_{i}, \psi_{i}\right\rangle \in \theta_{\Sigma}, i<n, \quad \text { imply }\left\langle\sigma_{\Sigma}\left(\phi_{0}, \ldots, \phi_{n-1}\right), \sigma_{\Sigma}\left(\psi_{0}, \ldots, \psi_{n-1}\right)\right\rangle \in \theta_{\Sigma},
$$

then $\theta$ is a said to be an $\mathrm{N}$-congruence system on SEN.

Let $\mathcal{J}=\langle$ Sign, SEN,$C\rangle$ be a $\pi$-institution, with $N$ a category of natural transformations on SEN. An N-congruence system $\theta$ on SEN is said to be a logical $\mathrm{N}$-congruence system of $\mathcal{J}$ if, for all $\Sigma \in|\operatorname{sign}|$ and all $\phi, \psi \in$ $\operatorname{SEN}(\Sigma),\langle\phi, \psi\rangle \in \theta_{\Sigma}$ implies that $\mathrm{C}_{\Sigma}(\phi)=\mathrm{C}_{\Sigma}(\psi)$. It was shown in [2I] that, under the signature-wise inclusion $\leqslant$, the collection $\operatorname{Con}^{N}(\mathcal{J})$ of all logical $N$ congruence systems of $\mathcal{J}$ forms a complete lattice $\operatorname{Con}^{N}(\mathcal{J})$, whence, there exists a largest logical $N$-congruence system of $\mathcal{J}$, which is denoted by $\widetilde{\Omega}^{N}(\mathcal{J})$ and is called the Tarski $\mathrm{N}$-congruence system of $\mathcal{J}$.

Given a $\pi$-institution $\mathcal{J}=\langle$ Sign, $\mathrm{SEN}, \mathrm{C}\rangle$, as above, with $\mathrm{N}$ a category of natural transformations on SEN, recall from 26 that a collection $\mathrm{T}=$ $\left\{T_{\Sigma}\right\}_{\Sigma \in \mid \text { Sign } \mid}$ of subsets $T_{\Sigma} \subseteq \operatorname{SEN}(\Sigma), \Sigma \in|\mathrm{Sign}|$, is called an axiom system of $\mathcal{J}$ if

$$
\operatorname{SEN}(f)\left(T_{\Sigma_{1}}\right) \subseteq T_{\Sigma_{2}}, \quad \text { for all } \quad \Sigma_{1}, \Sigma_{2} \in|\operatorname{Sign}|, f \in \operatorname{Sign}\left(\Sigma_{1}, \Sigma_{2}\right) .
$$

An axiom system is called a theory system [25] if, in addition, $T_{\Sigma}$ is a $\Sigma$-theory, for every $\Sigma \in \mid$ Sign|. To refer to a collection $T=\left\{T_{\Sigma}\right\}_{\Sigma \in \mid \text { Sign } \mid}$ of subsets $T_{\Sigma} \subseteq$ SEN $(\Sigma)$ that do not necessarily satisfy Condition (I) we will use the term axiom family (and theory family, if $T_{\Sigma}$ is a $\Sigma$-theory, for every $\Sigma \in|\operatorname{Sign}|$ ).

The collection ThFam (J) of theory families of a $\pi$-institution J ordered by signature-wise inclusion forms a complete lattice $\operatorname{ThFam}(\mathcal{J})=\langle\operatorname{ThFam}(\mathcal{J}), \leqslant\rangle$ and the same holds for the collection ThSys (J) of all theory systems under signature-wise inclusion $\leqslant$. Moreover it is not very hard to see that ThSys $(\mathcal{J})$ forms a complete sublattice of ThFam (J).

An $\mathrm{N}$-congruence system $\theta$ on SEN is said to be compatible with the axiom family $\mathrm{T}$, if, for all $\Sigma \in|\operatorname{Sign}|, \theta_{\Sigma}$ is compatible with $T_{\Sigma}$ in the usual sense, i.e., if, for all $\Sigma \in|\operatorname{Sign}|, \phi, \psi \in \operatorname{SEN}(\Sigma)$,

$$
\langle\phi, \psi\rangle \in \theta_{\Sigma} \quad \text { and } \quad \phi \in \mathrm{T}_{\Sigma} \quad \text { implies } \quad \psi \in \mathrm{T}_{\Sigma} .
$$

It was shown in Proposition 2.3 of [27] that there always exists a largest N-congruence system on SEN that is compatible with a given axiom family T. It is called the Leibniz $\mathrm{N}$-congruence system of $\mathrm{T}$ and denoted by $\Omega^{\mathrm{N}}(\mathrm{T})$.

In $[27$. Leibniz $N$-congruence systems are used to define the notion of an $N$ protoalgebraic $\pi$-institution. Namely, a $\pi$-institution $\mathcal{J}=\langle\operatorname{Sign}, \mathrm{SEN}, \mathrm{C}\rangle$, with 
$\mathrm{N}$ a category of natural transformations on SEN, is said to be $\mathrm{N}$-protoalgebraic if, for every theory family $\mathrm{T}=\left\{\mathrm{T}_{\Sigma}\right\}_{\Sigma \in \mid \text { Sign } \mid}$ of $\mathcal{J}$, every $\Sigma \in|\operatorname{Sign}|$ and all $\phi, \psi \in \operatorname{SEN}(\Sigma)$

$$
\langle\phi, \psi\rangle \in \Omega_{\Sigma}^{N}(T) \text { implies } C_{\Sigma}\left(T_{\Sigma} \cup\{\phi\}\right)=C_{\Sigma}\left(T_{\Sigma} \cup\{\psi\}\right) .
$$

In Lemma 3.8 of $[27]$, it is shown that a $\pi$-institution $\mathcal{J}=\langle\operatorname{Sign}, \mathrm{SEN}, \mathrm{C}\rangle$, with $\mathrm{N}$ a category of natural transformations on SEN, is $\mathrm{N}$-protoalgebraic if, for all $\mathrm{T}, \mathrm{T}^{\prime} \in \operatorname{ThFam}(\mathcal{J})$, we have that

$$
T \leqslant T^{\prime} \text { implies } \Omega^{N}(T) \leqslant \Omega^{N}\left(T^{\prime}\right),
$$

i.e., if and only if the N-Leibniz operator on the collection of all theory families of $\mathcal{J}$ is monotonic. Some other equivalent conditions are provided in [27], which also studies some additional properties of $\mathrm{N}$-protoalgebraic $\pi$-institutions. A further study of $\mathrm{N}$-protoalgebraicity is contained in $[28]$ and the interested reader is advised to consult these two references.

\section{N-Equivalence SyStems}

In this section, equivalence systems for $\pi$-institutions will be introduced taking after the systems of equivalence sentences of [7] (see also [18] and [6]). These systems are special cases of the parameterized equivalence systems, which were introduced in 28 for the $\pi$-institution framework, following preceding work on sentential logics in [4]. Some results, that are either special cases of or parallel results presented in [28], will be proved for $\pi$-institutions with equivalence systems, the so-called syntactically equivalential $\pi$-institutions. In the next section semantically equivalential $\pi$-institutions will be introduced, based on properties of their Leibniz operator, and it will be shown that syntactic equivalentiality implies semantic equivalentiality. The converse implication does not seem to hold in general in the $\pi$-institution framework, despite the fact that, as will be pointed out later when all relevant definitions are in place, it is true in the sentential logic framework.

DEFINition I Suppose that $\mathcal{J}=\langle\operatorname{Sign}, \mathrm{SEN}, \mathrm{C}\rangle$ is a $\pi$-institution and $\mathrm{N}$ a category of natural transformations on SEN. A collection $E=\left\{\epsilon^{i}: i \in I\right\}$, with $\epsilon^{i}: \operatorname{SEN}^{2} \rightarrow$ SEN in $N$, for all $i \in I$, is said to be an $N$-equivalence system for $\mathcal{J}$ if, for all $\sigma: \mathrm{SEN}^{n} \rightarrow \operatorname{SEN}$ in $\mathrm{N}, \Sigma \in|\operatorname{Sign}|, \phi, \psi \in \operatorname{SEN}(\Sigma)$, $\vec{\phi}, \vec{\psi} \in \operatorname{SEN}(\Sigma)^{n}$ and all theory families $T$ of $\mathcal{J}$,

I. $\mathrm{E}_{\Sigma}(\phi, \phi) \subseteq \mathrm{C}_{\Sigma}(\emptyset)$,

2. If $(\forall i)(\forall f)\left(E_{\Sigma^{\prime}}\left(\operatorname{SEN}(f)^{2}\left(\phi_{i}, \psi_{i}\right)\right) \subseteq T_{\Sigma^{\prime}}\right)$, then $(\forall f)\left(E_{\Sigma^{\prime}}\left(\operatorname{SEN}(f)^{2}\left(\sigma_{\Sigma}(\vec{\phi}), \sigma_{\Sigma}(\vec{\psi})\right)\right) \subseteq \mathrm{T}_{\Sigma^{\prime}}\right)$.

3. $\phi \in \mathrm{T}_{\Sigma}$ and $(\forall f)\left(\mathrm{E}_{\Sigma^{\prime}}\left(\operatorname{SEN}(\mathrm{f})^{2}(\phi, \psi)\right) \subseteq \mathrm{T}_{\Sigma^{\prime}}\right)$ imply $\psi \in \mathrm{T}_{\Sigma}$, 
where $(\forall f)$ is an abbreviation $(\forall f):=\left(\forall \Sigma^{\prime} \in|\operatorname{Sign}|\right)\left(\forall f \in \operatorname{Sign}\left(\Sigma, \Sigma^{\prime}\right)\right)$.

Let $\mathcal{J}=\langle$ Sign, SEN, $\mathrm{C}\rangle$ be a $\pi$-institution, with $\mathrm{N}$ a category of natural transformations on SEN, E a collection of natural transformations $\mathrm{SEN}^{2} \rightarrow$ SEN in $N$ and $T \in$ ThFam (J) a theory family of $\mathcal{J}$. Define the relation system $E(T)=\left\{E_{\Sigma}(T)\right\}_{\Sigma \in \mid \text { Sign } \mid}$, by setting, for all $\Sigma \in|\operatorname{Sign}|$,

$$
E_{\Sigma}(T)=\left\{\langle\phi, \psi\rangle \in \operatorname{SEN}(\Sigma)^{2}:(\forall f)\left(E_{\Sigma^{\prime}}\left(\operatorname{SEN}(f)^{2}(\phi, \psi)\right) \subseteq T_{\Sigma^{\prime}}\right)\right\}
$$

As in Proposition 4.I and Corollary 4.2 of [28], we obtain the following proposition stating that, if $E(T)$ happens to be reflexive, then it includes the $\mathrm{N}$-Leibniz congruence system corresponding to $\mathrm{T}$.

PROPOSITION 2 Let $\mathcal{J}=\langle$ Sign, SEN, $\mathrm{C}\rangle$ be a $\pi$-institution, with $\mathrm{N}$ a category of natural transformations on SEN, E a collection of natural transformations $\mathrm{SEN}^{2} \rightarrow$ $\mathrm{SEN}$ in $\mathrm{N}$ and $\mathrm{T} \in \mathrm{ThFam}(\mathrm{J})$. If $\mathrm{E}(\mathrm{T})$ is a reflexive relation system on $\mathrm{SEN}$, then $\Omega^{N}(T) \leqslant E(T)$.

Proof: If $\Sigma \in|\operatorname{Sign}|, \phi, \psi \in \operatorname{SEN}(\Sigma)$, such that $\langle\phi, \psi\rangle \in \Omega_{\Sigma}^{\mathrm{N}}(\mathrm{T})$, then, we have, by the N-congruence system property of $\Omega^{\mathrm{N}}(\mathrm{T})$, that, for all $\Sigma^{\prime} \in|\mathrm{Sign}|$ and all $f \in \operatorname{Sign}\left(\Sigma, \Sigma^{\prime}\right), \operatorname{SEN}(f)^{2}(\phi, \psi) \in \Omega_{\Sigma^{\prime}}^{N}(T)$. Thus, by the N-congruence property of $\Omega^{N}(T)$, we get that, for all $\epsilon \in E,\left\langle\epsilon_{\Sigma^{\prime}}\left(\operatorname{SEN}(f)^{2}(\phi, \phi)\right)\right.$, $\left.\epsilon_{\Sigma^{\prime}}\left(\operatorname{SEN}(f)^{2}(\phi, \psi)\right)\right\rangle \in \Omega_{\Sigma^{\prime}}^{N}(T)$, whence, since, by the reflexivity of $E(T)$, $\epsilon_{\Sigma^{\prime}}\left(\operatorname{SEN}(f)^{2}(\phi, \phi)\right) \in T_{\Sigma^{\prime}}$, we obtain, by the compatibility of $\Omega^{N}(T)$ with $T$, that $\epsilon_{\Sigma^{\prime}}\left(\operatorname{SEN}(f)^{2}(\phi, \psi)\right) \in T_{\Sigma^{\prime}}$, i.e., that $\langle\phi, \psi\rangle \in E_{\Sigma}(T)$. Hence $\Omega^{N}(T) \leqslant$ $E(T)$.

The analog of Corollary 4.2 of $[28]$ now says that, in case $E(T)$ happens to be an $\mathrm{N}$-congruence system on SEN that is compatible with $\mathrm{T}$, then it necessarily coincides with the $N$-Leibniz congruence system $\Omega^{N}(T)$. It is an immediate corollary of Proposition 2.

COROLlary 3 Let $\mathcal{J}=\langle$ Sign, SEN,$C\rangle$ be a $\pi$-institution, with $N$ a category of natural transformations on SEN, E a collection of natural transformations $\mathrm{SEN}^{2} \rightarrow \mathrm{SEN}$ in $\mathrm{N}$ and $\mathrm{T} \in \mathrm{ThFam}(\mathcal{J})$. If $E(T)$ is an $N$-congruence system on SEN that is compatible with $T$, then $E(T)=\Omega^{N}(T)$.

It is stated, next, that, if $E$ is an $N$-equivalence system for $\mathcal{J}$, then $E(T)$ is in fact an $\mathrm{N}$-congruence system on SEN that is compatible with $\mathrm{T}$, for every theory family $T$ of $\mathcal{J}$. This result summarizes Lemmas $4.3,4.4$ and 4.5 of $[28$ in the special case of an $\mathrm{N}$-equivalence system (without parameters). The proof will therefore be omitted, referring the interested reader to [28] for more details.

LEMMA 4 Let $\mathrm{J}=\langle$ Sign, SEN, $\mathrm{C}\rangle$ be a $\pi$-institution, with $\mathrm{N}$ a category of natural transformations on SEN, E an $\mathrm{N}$-equivalence system for $\mathrm{J}$ and $\mathrm{T} \in \mathrm{ThFam}(\mathrm{J})$. Then $\mathrm{E}(\mathrm{T})$ is an $\mathrm{N}$-congruence system on $\mathrm{SEN}$ that is compatible with $\mathrm{T}$. 
Corollary 3 and Lemma 4 lead directly to the following theorem, which is the analog of Theorem 4.6 of $[28]$ in the present setting and characterizes $\mathrm{N}$-equivalence systems.

THEOREM 5 Let $\mathcal{J}=\langle$ Sign, SEN, $\mathrm{C}\rangle$ be a $\pi$-institution, with $\mathrm{N}$ a category of natural transformations on SEN, and $\mathrm{E}$ a collection of natural transformations $\mathrm{SEN}^{2} \rightarrow \mathrm{SEN}$ in $\mathrm{N}$. E is an $\mathrm{N}$-equivalence system for $\mathrm{J}$ if and only if, for every $\mathrm{T} \in \operatorname{ThFam}(\mathcal{J}), \mathrm{E}(\mathrm{T})=\Omega^{\mathrm{N}}(\mathrm{T})$.

Theorem 5 has a series of corollaries.

COROLlary 6 Let $\mathcal{J}=\langle$ Sign, SEN,$C\rangle$ be a $\pi$-institution, with $N$ a category of natural transformations on SEN and $E, E^{\prime}$ two $N$-equivalence systems for $\mathcal{J}$. Then, for all theory families $T$ of $\mathcal{J}$ and for all $\Sigma \in|\operatorname{Sign}|, \phi, \psi \in \operatorname{SEN}(\Sigma)$,

$$
(\forall f)\left(E_{\Sigma^{\prime}}\left(\operatorname{SEN}(f)^{2}(\phi, \psi)\right) \subseteq T_{\Sigma^{\prime}}\right) \Leftrightarrow(\forall f)\left(E_{\Sigma^{\prime}}^{\prime}\left(\operatorname{SEN}(f)^{2}(\phi, \psi)\right) \subseteq T_{\Sigma^{\prime}}\right) .
$$

Proof: The conclusion follows directly from the observation that, for all $\mathrm{T} \in$ $\operatorname{ThFam}(\mathcal{J}), E(T)=\Omega^{\mathrm{N}}(\mathrm{T})=\mathrm{E}^{\prime}(\mathrm{T})$.

COROLlaRY 7 Let $\mathrm{J}=\langle$ Sign, SEN, C $\rangle$ be a $\pi$-institution, with $\mathrm{N}$ a category of natural transformations on SEN, and $E, E^{\prime}$ two collections of natural transformations $\mathrm{SEN}^{2} \rightarrow$ SEN in N. If, for all theory families T of $\mathcal{J}$ and all $\Sigma \in|\mathrm{Sign}|$, $\phi, \psi \in \operatorname{SEN}(\Sigma)$,

$$
(\forall f)\left(E_{\Sigma^{\prime}}\left(\operatorname{SEN}(f)^{2}(\phi, \psi)\right) \subseteq T_{\Sigma^{\prime}}\right) \Leftrightarrow(\forall f)\left(E_{\Sigma^{\prime}}^{\prime}\left(\operatorname{SEN}(f)^{2}(\phi, \psi)\right) \subseteq T_{\Sigma^{\prime}}\right),
$$

then $E$ is an $\mathrm{N}$-equivalence system for $\mathcal{J}$ if and only if $E^{\prime}$ is.

Proof: $E$ is an $N$-equivalence system for $\mathcal{J}$ if and only if $E(T)=\Omega^{N}(T)$ if and only if, by the hypothesis, $E^{\prime}(T)=\Omega^{N}(T)$ if and only if $E^{\prime}$ is an N-equivalence system for $\mathcal{J}$.

Given two $\pi$-institutions $\mathcal{J}=\langle$ Sign, SEN,$C\rangle$ and $\mathcal{J}^{\prime}=\left\langle\right.$ Sign, SEN, $\left.\mathrm{C}^{\prime}\right\rangle$ over the same sentence functors, such that $C \leqslant C^{\prime}$, it is not very difficult to see that, if $\mathcal{J}$ has an $\mathrm{N}$-equivalence system $\mathrm{E}$, then $\mathrm{E}$ is also an $\mathrm{N}$-equivalence system for $\mathrm{J}^{\prime}$.

Proposition 8 Let $\mathcal{J}=\langle$ Sign, SEN,$C\rangle$, J' $=\left\langle\right.$ Sign, SEN,$\left.C^{\prime}\right\rangle$ be $\pi$-institutions, with $\mathrm{N}$ a category of natural transformations on $\mathrm{SEN}$, such that $\mathrm{C} \leqslant \mathrm{C}^{\prime}$. If $\mathrm{E}$ is an $\mathrm{N}$-equivalence system for $\mathrm{J}$, then $\mathrm{E}$ is also an $\mathrm{N}$-equivalence system for $\mathrm{J}^{\prime}$.

Proof: Suppose that $T \in \operatorname{ThFam}\left(\mathcal{J}^{\prime}\right)$. Then, since $C \leqslant C^{\prime}, T \in \operatorname{ThFam}(\mathcal{J})$, whence, since $E$ is an $N$-equivalence system for $\mathcal{J}, E(T)=\Omega^{N}(T)$. This shows that $E$ is also an $\mathrm{N}$-equivalence system for $\mathcal{J}^{\prime}$.

It is shown, next, that every $\pi$-institution $\mathcal{J}$, with $N$ a category of natural transformations on $\mathrm{SEN}$, that has an $\mathrm{N}$-equivalence system is $\mathrm{N}$-protoalgebraic. 
PROPOSITION 9 Let $\mathrm{J}=\langle\mathrm{Sign}, \mathrm{SEN}, \mathrm{C}\rangle$ be a $\pi$-institution, with $\mathrm{N}$ a category of natural transformations on SEN. If J has an $\mathrm{N}$-equivalence system, then $\mathrm{J}$ is $\mathrm{N}$ protoalgebraic.

Proof: It suffices to show, by Lemma 3.8 of $[27]$, that $\Omega^{N}$ is monotone on the collection of theory families of $\mathcal{J}$. Suppose that $T, T^{\prime} \in \operatorname{ThFam}(\mathcal{J})$, such that $T \leqslant T^{\prime}$. Then, we have, for all $\Sigma \in \mid$ Sign $\mid$,

$$
\begin{aligned}
\Omega_{\Sigma}^{N}(T) & =E_{\Sigma}(T) \\
& =\left\{\langle\phi, \psi\rangle:(\forall f)\left(E_{\Sigma^{\prime}}\left(\operatorname{SEN}(f)^{2}(\phi, \psi)\right) \subseteq T_{\Sigma^{\prime}}\right)\right\} \\
& \subseteq\left\{\langle\phi, \psi\rangle:(\forall f)\left(E_{\Sigma^{\prime}}\left(\operatorname{SEN}(f)^{2}(\phi, \psi)\right) \subseteq T_{\Sigma^{\prime}}^{\prime}\right)\right\} \\
& =E_{\Sigma}\left(T^{\prime}\right) \\
& =\Omega_{\Sigma}^{N}\left(T^{\prime}\right)
\end{aligned}
$$

showing that $\Omega^{N}(T) \leqslant \Omega^{N}\left(T^{\prime}\right)$.

We close the section with the formulation and proof of a "transfer theorem" to the effect that an $\mathrm{N}$-equivalence system is carried to an $\mathrm{N}^{\prime}$-equivalence system via surjective $\left(\mathrm{N}, \mathrm{N}^{\prime}\right)$-logical morphisms.

THEOREM Io Let $\mathcal{J}=\langle\operatorname{Sign}, \mathrm{SEN}, \mathrm{C}\rangle, \mathcal{J}^{\prime}=\left\langle\mathrm{Sign}^{\prime}, \mathrm{SEN}^{\prime}, \mathrm{C}^{\prime}\right\rangle$ be two $\pi$ institutions, $\mathrm{N}, \mathrm{N}^{\prime}$ categories of natural transformations on $\mathrm{SEN}, \mathrm{SEN}^{\prime}$, respectively,

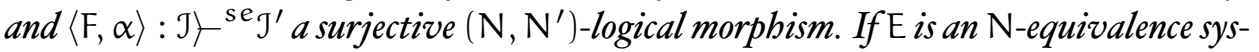
tem for $\mathcal{J}$, then the collection $\mathrm{E}^{\prime}$, corresponding to $\mathrm{E}$ via the $\left(\mathrm{N}, \mathrm{N}^{\prime}\right)$-epimorphic property, is an $\mathrm{N}^{\prime}$-equivalence system for $\mathrm{J}^{\prime}$.

Proof: The three properties of an $\mathrm{N}^{\prime}$-equivalence system will be shown to hold for $E^{\prime}$.

Suppose that $\Sigma^{\prime} \in\left|\operatorname{Sign}^{\prime}\right|, \phi^{\prime} \in \operatorname{SEN}^{\prime}\left(\Sigma^{\prime}\right)$. Then, there exists $\Sigma \in|\operatorname{Sign}|$, $\phi \in \operatorname{SEN}(\Sigma)$, such that $F(\Sigma)=\Sigma^{\prime}$ and $\alpha_{\Sigma}(\phi)=\phi^{\prime}$. Thus, we have

$$
\begin{aligned}
\mathrm{E}_{\Sigma^{\prime}}^{\prime}\left(\phi^{\prime}, \phi^{\prime}\right) & =\mathrm{E}_{\mathrm{F}(\Sigma)}^{\prime}\left(\alpha_{\Sigma}(\phi), \alpha_{\Sigma}(\phi)\right) \\
& =\alpha_{\Sigma}\left(\mathrm{E}_{\Sigma}(\phi, \phi)\right) \\
& \subseteq \alpha_{\Sigma}\left(\mathrm{C}_{\Sigma}(\emptyset)\right) \\
& \subseteq \mathrm{C}_{\mathrm{F}(\Sigma)}^{\prime}\left(\alpha_{\Sigma}(\emptyset)\right) \\
& =\mathrm{C}_{\Sigma^{\prime}}^{\prime}(\emptyset) .
\end{aligned}
$$

Suppose, now, that $\Sigma \in|\operatorname{Sign}|, \sigma: \operatorname{SEN}^{n} \rightarrow \operatorname{SEN}$ is in $N$ and $\vec{\phi}, \vec{\psi} \in \operatorname{SEN}(\Sigma)^{n}$. Let $T^{\prime}$ be a theory family of $\mathcal{J}^{\prime}$ and recall that, in that case, $\alpha^{-1}\left(T^{\prime}\right)$, defined by

$$
\alpha^{-1}\left(\mathrm{~T}^{\prime}\right)=\left\{\alpha_{\Sigma}^{-1}\left(\mathrm{~T}_{\mathrm{F}(\Sigma)}^{\prime}\right)\right\}_{\Sigma \in \mid \text { Sign } \mid},
$$

is a theory family of $\mathcal{J}$. We have, for all $i<n$ and all $\Sigma^{\prime} \in|\mathrm{Sign}|$, $f \in \operatorname{Sign}\left(\Sigma, \Sigma^{\prime}\right), E_{F\left(\Sigma^{\prime}\right)}^{\prime}\left(\operatorname{SEN}^{\prime}(F(f))^{2}\left(\alpha_{\Sigma}^{2}\left(\phi_{i}, \psi_{i}\right)\right)\right) \subseteq T_{F\left(\Sigma^{\prime}\right)}^{\prime}$ implies

$$
E_{F\left(\Sigma^{\prime}\right)}^{\prime}\left(\alpha_{\Sigma^{\prime}}^{2}\left(\operatorname{SEN}(f)^{2}\left(\phi_{i}, \psi_{i}\right)\right)\right) \subseteq T_{F\left(\Sigma^{\prime}\right)}^{\prime}
$$


implies $\alpha_{\Sigma^{\prime}}\left(E_{\Sigma^{\prime}}\left(\operatorname{SEN}(f)^{2}\left(\phi_{i}, \psi_{i}\right)\right)\right) \subseteq T_{F\left(\Sigma^{\prime}\right)}^{\prime}$ whence,

$$
E_{\Sigma^{\prime}}\left(\operatorname{SEN}(f)^{2}\left(\phi_{i}, \psi_{i}\right)\right) \subseteq \alpha_{\Sigma^{\prime}}^{-1}\left(T_{F\left(\Sigma^{\prime}\right)}^{\prime}\right)
$$

Therefore, by the hypothesis, we obtain

$$
\operatorname{E}_{\Sigma^{\prime}}\left(\operatorname{SEN}(f)^{2}\left(\sigma_{\Sigma}(\vec{\phi}), \sigma_{\Sigma}(\vec{\psi})\right)\right) \subseteq \alpha_{\Sigma^{\prime}}^{-1}\left(T_{F\left(\Sigma^{\prime}\right)}^{\prime}\right) .
$$

This implies that

$$
\alpha_{\Sigma^{\prime}}\left(\mathrm{E}_{\Sigma^{\prime}}\left(\operatorname{SEN}(f)^{2}\left(\sigma_{\Sigma}(\vec{\phi}), \sigma_{\Sigma}(\vec{\psi})\right)\right)\right) \subseteq \mathrm{T}_{\mathrm{F}\left(\Sigma^{\prime}\right)}^{\prime}
$$

giving that

$$
\mathrm{E}_{\mathrm{F}\left(\Sigma^{\prime}\right)}^{\prime}\left(\alpha_{\Sigma^{\prime}}^{2}\left(\operatorname{SEN}(\mathrm{f})^{2}\left(\sigma_{\Sigma}(\vec{\phi}), \sigma_{\Sigma}(\vec{\psi})\right)\right)\right) \subseteq \mathrm{T}_{\mathrm{F}\left(\Sigma^{\prime}\right)}^{\prime},
$$

which implies that

$$
\mathrm{E}_{\mathrm{F}\left(\Sigma^{\prime}\right)}^{\prime}\left(\operatorname{SEN}^{\prime}(\mathrm{F}(\mathrm{f}))^{2}\left(\alpha_{\Sigma}^{2}\left(\sigma_{\Sigma}(\vec{\phi}), \sigma_{\Sigma}(\vec{\psi})\right)\right)\right) \subseteq \mathrm{T}_{\mathrm{F}\left(\Sigma^{\prime}\right)}^{\prime}
$$

and, therefore, we obtain the required

$$
E_{F\left(\Sigma^{\prime}\right)}^{\prime}\left(\operatorname{SEN}^{\prime}(F(f))^{2}\left(\sigma_{F(\Sigma)}^{\prime}\left(\alpha_{\Sigma}^{n}(\vec{\phi})\right), \sigma_{F(\Sigma)}^{\prime}\left(\alpha_{\Sigma}^{n}(\vec{\psi})\right)\right)\right) \subseteq \mathrm{T}_{\mathrm{F}\left(\Sigma^{\prime}\right)}^{\prime} .
$$

Finally, for the last condition, suppose that $\Sigma \in|\operatorname{Sign}|, \phi, \psi \in \operatorname{SEN}(\Sigma)$, $\mathrm{T}^{\prime} \in \operatorname{ThFam}\left(\mathcal{J}^{\prime}\right)$, such that $\alpha_{\Sigma}(\phi) \in \mathrm{T}_{\mathrm{F}(\Sigma)}^{\prime}$ and, for all $\Sigma^{\prime} \in|\operatorname{Sign}|, f \in$ $\operatorname{Sign}\left(\Sigma, \Sigma^{\prime}\right)$,

$$
\mathrm{E}_{\mathrm{F}\left(\Sigma^{\prime}\right)}^{\prime}\left(\operatorname{SEN}^{\prime}(\mathrm{F}(\mathrm{f}))^{2}\left(\alpha_{\Sigma}^{2}(\phi, \psi)\right)\right) \subseteq \mathrm{T}_{\mathrm{F}\left(\Sigma^{\prime}\right)}^{\prime}
$$

Then, following the same steps followed above for the proof of the second condition, we obtain that $\phi \in \alpha_{\Sigma}^{-1}\left(\mathrm{~T}_{\mathrm{F}(\Sigma)}^{\prime}\right)$ and, for every $\Sigma^{\prime} \in|\operatorname{Sign}|, \mathrm{f} \in$ $\operatorname{Sign}\left(\Sigma, \Sigma^{\prime}\right), E_{\Sigma^{\prime}}\left(\operatorname{SEN}(f)^{2}(\phi, \psi)\right) \subseteq \alpha_{\Sigma^{\prime}}^{-1}\left(T_{F\left(\Sigma^{\prime}\right)}^{\prime}\right)$. Therefore, by the hypothesis, we get that $\psi \in \alpha_{\Sigma}^{-1}\left(\mathrm{~T}_{\mathrm{F}(\Sigma)}^{\prime}\right)$, which yields that $\alpha_{\Sigma}(\psi) \in \mathrm{T}_{\mathrm{F}(\Sigma)}^{\prime}$.

Theorem IO combined with Theorem 5 , allows the formulation of the following alternative criterion for a collection of natural transformations to be an equivalence system for a given $\pi$-institution.

THEOREM II Let J = 〈Sign, SEN, C $\rangle$ be a $\pi$-institution, with $\mathrm{N}$ a category of natural transformations on $\mathrm{SEN}$, and $\mathrm{E}$ a collection of natural transformations $\mathrm{SEN}^{2} \rightarrow \mathrm{SEN}$ in $\mathrm{N}$. E is an $\mathrm{N}$-equivalence system for J if and only if, for all functors $\mathrm{SEN}^{\prime}: \mathrm{Sign}^{\prime} \rightarrow$ Set, with category of natural transformations $\mathrm{N}^{\prime}$ on $\mathrm{SEN}^{\prime}$, and all surjective $\left(\mathrm{N}, \mathrm{N}^{\prime}\right)$ epimorphic translations $\langle\mathrm{F}, \alpha\rangle: \mathrm{SEN} \rightarrow{ }^{\text {se }} \mathrm{SEN}^{\prime}$, we have $\mathrm{E}^{\prime}(\mathrm{T})=\Omega^{\mathrm{N}^{\prime}}(\mathrm{T})$, for all $\mathrm{T} \in \operatorname{ThFam}_{\mathfrak{J}}^{\langle\mathrm{F}, \alpha\rangle}\left(\mathrm{SEN}^{\prime}\right)$, where $\mathrm{E}^{\prime}$ is the collection corresponding to $\mathrm{E}$ via the $\left(\mathrm{N}, \mathrm{N}^{\prime}\right)$-epimorphic property.

In Theorem II the notation $\operatorname{ThFam}_{\mathcal{J}}^{\langle\mathrm{F}, \alpha\rangle}\left(\mathrm{SEN}^{\prime}\right)$ refers to the collection of theory families of the $\langle F, \alpha\rangle$-min $\left(N, N^{\prime}\right)$-model of J on SEN'. For the definition of min models and related notation, the reader is referred to [22]. 


\section{N-LEIBNIZ CONGRUENCE SYSTEMS}

Let $\mathcal{J}=\langle$ Sign, SEN,$C\rangle$ be a $\pi$-institution, with $N$ a category of natural transformations on SEN. Denote by $E^{\mathrm{m}}$ the subcollection of all natural transformations $\epsilon: \mathrm{SEN}^{2} \rightarrow \mathrm{SEN}$ in $\mathrm{N}$, such that, for all $\Sigma \in|\operatorname{Sign}|, \phi \in \operatorname{SEN}(\Sigma)$, $\epsilon_{\Sigma}(\phi, \phi) \in \mathrm{C}_{\Sigma}(\emptyset)$.

$$
\begin{aligned}
\mathrm{E}^{\mathrm{m}}= & \left\{\epsilon: \mathrm{SEN}^{2} \rightarrow \mathrm{SEN}\right. \text { in N : } \\
& \left.(\forall \Sigma \in|\operatorname{Sign}|)(\forall \phi \in \operatorname{SEN}(\Sigma))\left(\epsilon_{\Sigma}(\phi, \phi) \in \mathrm{C}_{\Sigma}(\emptyset)\right)\right\} .
\end{aligned}
$$

It is shown that the $\pi$-institution $\mathcal{J}$ has an $N$-equivalence system $E$ if and only if $\mathrm{E}^{\mathrm{m}}$ is also an $\mathrm{N}$-equivalence system of $\mathcal{J}$. This will immediately yield that $\mathrm{E}^{\mathrm{m}}$ is actually the largest $\mathrm{N}$-equivalence system of $\mathcal{J}$ in case $\mathcal{J}$ has an $\mathrm{N}$-equivalence system.

THEOREM I2 Let $\mathrm{J}=\langle\mathrm{Sign}, \mathrm{SEN}, \mathrm{C}\rangle$ be a $\pi$-institution, with $\mathrm{N}$ a category of natural transformations on $\mathrm{SEN}$, and $\mathrm{E}$ a collection of natural transformations $\mathrm{SEN}^{2} \rightarrow \mathrm{SEN}$ in $\mathrm{N}$. If $\mathrm{E}$ is an $\mathrm{N}$-equivalence system for $\mathrm{J}$, then, for all $\mathrm{T} \in \operatorname{ThFam}(\mathcal{J}), \Sigma \in|\mathrm{Sign}|$, $\phi, \psi \in \operatorname{SEN}(\Sigma)$,

$$
(\forall f)\left(E_{\Sigma^{\prime}}\left(\operatorname{SEN}(f)^{2}(\phi, \psi)\right) \subseteq T_{\Sigma^{\prime}}\right) \Leftrightarrow(\forall f)\left(\operatorname{E}_{\Sigma^{\prime}}^{m}\left(\operatorname{SEN}(f)^{2}(\phi, \psi)\right) \subseteq T_{\Sigma^{\prime}}\right) .
$$

Proof: Suppose that $\mathrm{E}$ is an N-equivalence for J. Note that, in this case, for all $\Sigma \in|\operatorname{Sign}|, \phi \in \operatorname{SEN}(\Sigma), \epsilon_{\Sigma}(\phi, \phi) \subseteq \mathrm{C}_{\Sigma}(\emptyset)$, for all $\epsilon \in \mathrm{E}$. Therefore $E \subseteq E^{m}$. This immediately yields that, if $(\forall f)\left(E_{\Sigma^{\prime}}^{m}\left(\operatorname{SEN}(f)^{2}(\phi, \psi)\right) \subseteq T_{\Sigma^{\prime}}\right)$, then $(\forall f)\left(E_{\Sigma^{\prime}}\left(\operatorname{SEN}(f)^{2}(\phi, \psi)\right) \subseteq T_{\Sigma^{\prime}}\right)$, i.e., the right-to-left implication in the conclusion.

Suppose, conversely, that $(\forall f)\left(E_{\Sigma^{\prime}}\left(\operatorname{SEN}(f)^{2}(\phi, \psi)\right) \subseteq T_{\Sigma^{\prime}}\right)$. Then $\langle\phi, \psi\rangle \in E_{\Sigma}(T)$ and, since $E$ is an $N$-equivalence system for $\mathcal{J}$, we obtain, by Theorem 5. $\langle\phi, \psi\rangle \in \Omega_{\Sigma}^{N}(T)$. Therefore, since $\Omega^{N}(T)$ is an N-congruence system, we obtain, for all $\epsilon \in \mathrm{E}^{\mathrm{m}}, \Sigma^{\prime} \in|\operatorname{Sign}|, f \in \operatorname{Sign}\left(\Sigma, \Sigma^{\prime}\right)$,

$$
\left\langle\epsilon_{\Sigma^{\prime}}\left(\operatorname{SEN}(f)^{2}(\phi, \phi)\right), \epsilon_{\Sigma^{\prime}}\left(\operatorname{SEN}(f)^{2}(\phi, \psi)\right)\right\rangle \in \Omega_{\Sigma^{\prime}}^{N}(T),
$$

whence, since $\epsilon \in \mathrm{E}^{\mathrm{m}}$ implies $\epsilon_{\Sigma^{\prime}}\left(\operatorname{SEN}(f)^{2}(\phi, \phi)\right) \in \mathrm{C}_{\Sigma^{\prime}}(\emptyset) \subseteq \mathrm{T}_{\Sigma^{\prime}}$, we get, by the compatibility of $\Omega^{\mathrm{N}}(\mathrm{T})$ with $\mathrm{T}$, that $\epsilon_{\Sigma^{\prime}}\left(\operatorname{SEN}(f)^{2}(\phi, \psi)\right) \in \mathrm{T}_{\Sigma^{\prime}}$. This shows that

$$
(\forall f)\left(\operatorname{Ex}_{\Sigma^{\prime}}^{\mathrm{m}}\left(\operatorname{SEN}(f)^{2}(\phi, \psi)\right) \subseteq \mathrm{T}_{\Sigma^{\prime}}\right)
$$

and concludes the proof of the left-to-right implication in the conclusion.

Theorem 12 shows that the property of having an $\mathrm{N}$-equivalence system may be characterized by the property of $\mathrm{E}^{\mathrm{m}}$ being an $\mathrm{N}$-equivalence system. 
THEOREM I3 Let $\mathrm{J}=\langle\mathrm{Sign}, \mathrm{SEN}, \mathrm{C}\rangle$ be a $\pi$-institution, with $\mathrm{N}$ a category of natural transformations on SEN. J has an $\mathrm{N}$-equivalence system if and only if $\mathrm{E}^{\mathrm{m}}$ is an $\mathrm{N}$ equivalence system for $\mathrm{J}$. Moreover, in this case, $\mathrm{E}^{\mathrm{m}}$ is the largest $\mathrm{N}$-equivalence system for J.

Proof: The "if" statement is obvious. The "only if" follows directly from Theorem 12 and Corollary 7 . Finally, the last statement also follows from Theorem 12 and the fact that, for every $\mathrm{N}$-equivalence system $\mathrm{E}$, every $\epsilon \in \mathrm{E}$ satisfies $\epsilon_{\Sigma}(\phi, \phi) \in \mathrm{C}_{\Sigma}(\emptyset)$, for all $\Sigma \in|\operatorname{Sign}|$ and all $\phi \in \operatorname{SEN}(\Sigma)$.

Next, a characterization of those $\pi$-institutions possessing an $\mathrm{N}$ equivalence system inside the class of $\mathrm{N}$-protoalgebraic $\pi$-institutions will be provided. The result will form an analog of Herrmann's Test (I6); also Theorem 3.3.3 of [7]). To introduce this result, a construction that makes sense in any $\pi$-institution is needed.

Suppose that $\mathcal{J}=\langle\operatorname{Sign}, \mathrm{SEN}, \mathrm{C}\rangle$ is a $\pi$-institution, $N$ a category of natural transformations on SEN and $E$ a collection of natural transformations $\mathrm{SEN}^{2} \rightarrow$ SEN in N. For all $\Sigma_{0} \in|\operatorname{Sign}|, \phi, \psi \in \operatorname{SEN}\left(\Sigma_{0}\right)$, define the theory system $E^{\left\langle\Sigma_{0}, \phi, \psi\right\rangle}=\left\{E_{\Sigma}^{\left\langle\Sigma_{0}, \phi, \psi\right\rangle}\right\}_{\Sigma \in \mid \text { Sign } \mid}$ of J by setting, for all $\Sigma \in \mid$ Sign $\mid$,

$$
E_{\Sigma}^{\left\langle\Sigma_{0}, \phi, \psi\right\rangle}=C_{\Sigma}\left(\left\{E_{\Sigma}\left(\operatorname{SEN}(f)^{2}(\phi, \psi)\right): f \in \operatorname{Sign}\left(\Sigma_{0}, \Sigma\right)\right\}\right) .
$$

It is not difficult to prove that $\mathrm{E}^{\left\langle\Sigma_{0}, \phi, \psi\right\rangle}$ is in fact a theory system of $\mathcal{J}$. Proposition I4 Suppose that $\mathcal{J}=\langle$ Sign, SEN, C $\rangle$ is a $\pi$-institution, $N$ a category of natural transformations on $\mathrm{SEN}$ and $\mathrm{E}$ a collection of natural transformations $\mathrm{SEN}^{2} \rightarrow \operatorname{SEN}$ in $\mathrm{N}$. For all $\Sigma_{0} \in|\operatorname{Sign}|, \phi, \psi \in \operatorname{SEN}\left(\Sigma_{0}\right), \mathrm{E}^{\left\langle\Sigma_{0}, \phi, \psi\right\rangle}$ is a theory system of J.

Proof: Since $\mathrm{E}^{\left\langle\Sigma_{0}, \phi, \psi\right\rangle}$ is clearly a theory family, it suffices to show that, for all $\Sigma, \Sigma^{\prime} \in|\operatorname{Sign}|, g \in \operatorname{Sign}\left(\Sigma, \Sigma^{\prime}\right), \operatorname{SEN}(g)\left(E_{\Sigma}^{\left\langle\Sigma_{0}, \phi, \psi\right\rangle}\right) \subseteq E_{\Sigma^{\prime}}^{\left\langle\Sigma_{0}, \phi, \psi\right\rangle}$. We have

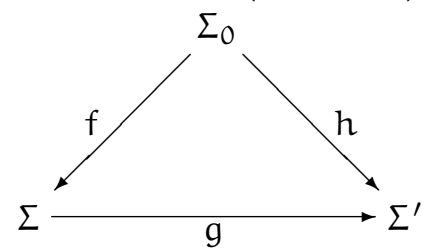

$$
\begin{aligned}
\operatorname{SEN}(g) & \left(E_{\Sigma}^{\left\langle\Sigma_{0}, \phi, \psi\right\rangle}\right) \\
& =\operatorname{SEN}(g)\left(C_{\Sigma}\left(\left\{E_{\Sigma}\left(\operatorname{SEN}(f)^{2}(\phi, \psi)\right): f \in \operatorname{Sign}\left(\Sigma_{0}, \Sigma\right)\right\}\right)\right) \\
& \subseteq C_{\Sigma^{\prime}}\left(\operatorname{SEN}(g)\left(\left\{E_{\Sigma}\left(\operatorname{SEN}(f)^{2}(\phi, \psi)\right): f \in \operatorname{Sign}\left(\Sigma_{0}, \Sigma\right)\right\}\right)\right) \\
& =C_{\Sigma^{\prime}}\left(\left\{E_{\Sigma^{\prime}}\left(\operatorname{SEN}(g f)^{2}(\phi, \psi)\right): f \in \operatorname{Sign}\left(\Sigma_{0}, \Sigma\right)\right\}\right) \\
& \subseteq C_{\Sigma^{\prime}}\left(\left\{E_{\Sigma^{\prime}}\left(\operatorname{SEN}(h)^{2}(\phi, \psi)\right): h \in \operatorname{Sign}\left(\Sigma_{0}, \Sigma^{\prime}\right)\right\}\right) \\
& =E_{\Sigma^{\prime}}^{\left\langle\Sigma_{0}, \phi, \psi\right\rangle}
\end{aligned}
$$


The framework is now in place in order to proceed with the formulation and proof of the analog of Herrmann's Test for $\pi$-institutions.

THEOREM 15 (herrmann's test) Suppose that J $=\langle$ Sign, SEN, C $\rangle$, with $\mathrm{N}$ a category of natural transformations on $\mathrm{SEN}$, is an $\mathrm{N}$-protoalgebraic $\pi$-institution, and $\mathrm{E}$ a collection of natural transformations $\mathrm{SEN}^{2} \rightarrow \mathrm{SEN}$ in $\mathrm{N}$. E is an $\mathrm{N}$-equivalence system for $\mathcal{J}$ if and only if, for all $\Sigma \in|\operatorname{Sign}|, \phi, \psi \in \operatorname{SEN}(\Sigma)$,

$$
\mathrm{E}_{\Sigma}(\phi, \phi) \subseteq \mathrm{C}_{\Sigma}(\emptyset) \quad \text { and } \quad\langle\phi, \psi\rangle \in \Omega_{\Sigma}^{\mathrm{N}}\left(\mathrm{E}^{\langle\Sigma, \phi, \psi\rangle}\right) .
$$

Proof: Suppose that the two conditions in (2) hold for E. By Theorem 5 , it suffices to show that, for every $T \in \operatorname{ThFam}(\mathcal{J}), E(T)=\Omega^{N}(T)$.

Suppose, first, that $\Sigma \in|\operatorname{Sign}|, \phi, \psi \in \operatorname{SEN}(\Sigma)$, such that $\langle\phi, \psi\rangle \in \mathrm{E}_{\Sigma}(\mathrm{T})$. This implies, by the definition of $E(T)$, that

$$
(\forall f)\left(E_{\Sigma^{\prime}}\left(\operatorname{SEN}(f)^{2}(\phi, \psi)\right) \subseteq T_{\Sigma^{\prime}}\right) \text {. }
$$

Therefore,

$$
\mathrm{C}_{\Sigma^{\prime}}\left(\left\{\mathrm{E}_{\Sigma^{\prime}}\left(\operatorname{SEN}(\mathrm{f})^{2}(\phi, \psi)\right): \mathrm{f} \in \operatorname{Sign}\left(\Sigma, \Sigma^{\prime}\right)\right\}\right) \subseteq \mathrm{T}_{\Sigma^{\prime}} .
$$

This shows that, for all $\Sigma^{\prime} \in|\operatorname{Sign}|, \mathrm{E}_{\Sigma,}^{\langle\Sigma, \phi, \psi\rangle} \subseteq \mathrm{T}_{\Sigma^{\prime}}$, i.e., that $\mathrm{E}^{\langle\Sigma, \phi, \psi\rangle} \leqslant \mathrm{T}$. Thus, by N-protoalgebraicity, $\Omega^{\mathrm{N}}\left(\mathrm{E}^{\langle\Sigma, \phi, \psi\rangle}\right) \leqslant \Omega^{\mathrm{N}}(\mathrm{T})$, and, since, by Condition (2), $\langle\phi, \psi\rangle \in \Omega_{\Sigma}^{N}\left(E^{\langle\Sigma, \phi, \psi\rangle}\right)$, we obtain that $\langle\phi, \psi\rangle \in \Omega_{\Sigma}^{N}(T)$. This concludes the proof that $E_{\Sigma}(T) \subseteq \Omega_{\Sigma}^{N}(T)$ and, this holding for an arbitrary $\Sigma \in \mid$ Sign $\mid$, we have $E(T) \leqslant \Omega^{N}(T)$.

Suppose, for the reverse inclusion, that $\Sigma \in|\operatorname{Sign}|, \phi, \psi \in \operatorname{SEN}(\Sigma)$, such that $\langle\phi, \psi\rangle \in \Omega_{\Sigma}^{N}(T)$. Then, since $E$ is a subcollection of natural transformations in $N$ and $\Omega^{N}(T)$ is an N-congruence system, we get that, for every $\Sigma^{\prime} \in|\operatorname{Sign}|, f \in \operatorname{Sign}\left(\Sigma, \Sigma^{\prime}\right)$,

$$
\left\langle\epsilon_{\Sigma^{\prime}}\left(\operatorname{SEN}(f)^{2}(\phi, \psi)\right), \epsilon_{\Sigma^{\prime}}\left(\operatorname{SEN}(f)^{2}(\phi, \phi)\right)\right\rangle \in \Omega_{\Sigma^{\prime}}^{N}(T),
$$

for all $\epsilon \in$ E. But, by Condition (2), $\epsilon_{\Sigma^{\prime}}\left(\operatorname{SEN}(f)^{2}(\phi, \phi)\right) \in \mathrm{C}_{\Sigma^{\prime}}(\emptyset) \subseteq \mathrm{T}_{\Sigma^{\prime}}$, for all $\epsilon \in E$, whence, by the compatibility property of $\Omega^{N}(T)$ with $T$, $\epsilon_{\Sigma^{\prime}}\left(\operatorname{SEN}(f)^{2}(\phi, \psi)\right) \in \mathrm{T}_{\Sigma^{\prime}}$, for all $\epsilon \in \mathrm{E}$, i.e., $\mathrm{E}_{\Sigma^{\prime}}\left(\operatorname{SEN}(f)^{2}(\phi, \psi)\right) \subseteq \mathrm{T}_{\Sigma^{\prime}}$. Since this holds for arbitrary $\Sigma^{\prime} \in|\operatorname{Sign}|$ and arbitrary $f \in \operatorname{Sign}\left(\Sigma, \Sigma^{\prime}\right)$, we obtain that $\langle\phi, \psi\rangle \in \mathrm{E}_{\Sigma}(\mathrm{T})$. Thus, we have $\Omega_{\Sigma}^{\mathrm{N}}(\mathrm{T}) \subseteq \mathrm{E}_{\Sigma}(\mathrm{T})$. Now $\Sigma \in|\mathrm{Sign}|$ being arbitrary, we get that $\Omega^{N}(T) \leqslant E(T)$.

Suppose, conversely, that $E$ is an $N$-equivalence system for $\mathcal{J}$. Since the first condition in 2) is part of the definition of an $\mathrm{N}$-equivalence system, it 
suffices to prove that the second condition in (2) is also satisfied. By Theorem 5. we have that $E(T)=\Omega^{N}(T)$, for every theory family $T$ of $\mathcal{J}$. In particular, we obtain that, for all $\Sigma \in|\operatorname{Sign}|, \phi, \psi \in \operatorname{SEN}(\Sigma), E_{\Sigma}(E\langle\Sigma, \phi, \psi\rangle)=$ $\Omega_{\Sigma}^{N}\left(E^{\langle\Sigma, \phi, \psi\rangle}\right)$. Thus, it suffices to show that $\langle\phi, \psi\rangle \in E_{\Sigma}\left(E^{\langle\Sigma, \phi, \psi\rangle}\right)$, i.e., that $(\forall f)\left(E_{\Sigma^{\prime}}\left(\operatorname{SEN}(f)^{2}(\phi, \psi)\right) \subseteq E_{\Sigma}^{\langle\Sigma, \phi, \psi\rangle}\right)$. This is equivalent to

$$
\epsilon_{\Sigma^{\prime}}\left(\operatorname{SEN}(f)^{2}(\phi, \psi)\right) \in \mathrm{C}_{\Sigma^{\prime}}\left(\left\{\operatorname{E}_{\Sigma^{\prime}}\left(\operatorname{SEN}(f)^{2}(\phi, \psi)\right): f \in \operatorname{Sign}\left(\Sigma, \Sigma^{\prime}\right)\right\}\right),
$$

for all $\epsilon \in \mathrm{E}, \Sigma^{\prime} \in|\operatorname{Sign}|, f \in \operatorname{Sign}\left(\Sigma, \Sigma^{\prime}\right)$. But this is obvious because of the reflexivity property of $C$.

Now consider a $\pi$-institution $\mathcal{J}=\langle\operatorname{Sign}, \mathrm{SEN}, \mathrm{C}\rangle$, with $\mathrm{N}$ a category of natural transformations on SEN, a functor $\mathrm{SEN}^{\prime}: \mathrm{Sign}^{\prime} \rightarrow$ Set, with $\mathrm{N}^{\prime}$ a category of natural transformations on $\mathrm{SEN}^{\prime}$, and an $\left(\mathrm{N}, \mathrm{N}^{\prime}\right)$-epimorphic translation $\langle F, \alpha\rangle: \mathrm{SEN} \rightarrow{ }^{\text {se }} \mathrm{SEN}^{\prime}$. Given a theory family $\mathrm{T}^{\prime} \in \operatorname{ThFam}_{\mathcal{J}}^{\langle\mathrm{F}, \alpha\rangle}\left(\mathrm{SEN}^{\prime}\right)$ of the $\langle F, \alpha\rangle$-min model of $\mathcal{J}$ on $\mathrm{SEN}^{\prime}$, recall that the collection $\alpha^{-1}\left(\mathrm{~T}^{\prime}\right)=\mathrm{T}=$ $\left\{T_{\Sigma}\right\}_{\Sigma \in|\operatorname{Sign}|}$, defined, for all $\Sigma \in|\operatorname{Sign}|$, by $T_{\Sigma}=\alpha_{\Sigma}^{-1}\left(T_{F(\Sigma)}^{\prime}\right)$, is a theory family of $\mathcal{J}$.

If, moreover, $\langle F, \alpha\rangle: \mathcal{J}\rangle \mathcal{J}^{\prime}$ is an $\left(\mathrm{N}, \mathrm{N}^{\prime}\right)$-logical morphism, with $\mathrm{F}$ an isomorphism, then, given a theory family $T \in \operatorname{ThFam}(\mathcal{J})$, the collection $\mathrm{C}^{\prime}(\alpha(\mathrm{T}))=\mathrm{T}^{\prime}=\left\{\mathrm{T}_{\Sigma^{\prime}}^{\prime}\right\}_{\Sigma^{\prime} \in\left|\mathrm{Sign}^{\prime}\right|}$, defined, for all $\Sigma^{\prime} \in\left|\mathrm{Sign}^{\prime}\right|$, by $\mathrm{T}_{\Sigma^{\prime}}^{\prime}=\mathrm{C}_{\Sigma^{\prime}}^{\prime}\left(\alpha_{\mathrm{F}^{-1}\left(\Sigma^{\prime}\right)}\left(\mathrm{T}_{\mathrm{F}^{-1}\left(\Sigma^{\prime}\right)}\right)\right)$ is obviously a theory family of $\mathcal{J}^{\prime}$.

Both $\alpha^{-1}(T)$ and $C^{\prime}(\alpha(T))$, as defined above, will be used in the formulation of the following theorem, which forms a partial analog of Theorem 3.3.4 of $[7]$.

THEOREM I6 Let $\mathrm{J}=\langle\mathrm{Sign}, \mathrm{SEN}, \mathrm{C}\rangle$ be a $\pi$-institution and $\mathrm{N}$ a category of natural transformations on SEN. Then the following statements are related by $(1 \leftrightarrow 2) \rightarrow 3 \rightarrow$ 4:

I. J has an $\mathrm{N}$-equivalence system $\mathrm{E}$.

2. The collection $\mathrm{E}^{\mathrm{m}}$ satisfies Properties 2 and 3 of Definition $\mathrm{T}$

3. The $\mathrm{N}$-Leibniz operator $\Omega^{\mathrm{N}}$ is monotone on theory families and, for every $(\mathrm{N}, \mathrm{N})$-logical morphism $\langle\mathrm{F}, \alpha\rangle: \mathcal{J}\rangle^{\mathrm{se}}{ }^{\mathrm{J}}$, with $\mathrm{F}$ surjective,

$$
\alpha^{-1}\left(\Omega^{\mathrm{N}}(\mathrm{T})\right)=\Omega^{\mathrm{N}}\left(\alpha^{-1}(\mathrm{~T})\right), \quad \text { for all } \mathrm{T} \in \mathrm{ThFam}(\mathcal{J}) .
$$

4. The $\mathrm{N}$-Leibniz operator $\Omega^{\mathrm{N}}$ is monotone on theory families and, for every $(\mathrm{N}, \mathrm{N})$-logical morphism $\langle\mathrm{F}, \alpha\rangle: \mathcal{J}\rangle-{ }^{\mathrm{se}} \mathcal{J}$, with $\mathrm{F}$ an isomorphism,

$$
\alpha\left(\Omega^{\mathrm{N}}(\mathrm{T})\right) \leqslant \Omega^{\mathrm{N}}(\mathrm{C}(\alpha(\mathrm{T}))), \text { for all } \mathrm{T} \in \operatorname{ThFam}(\mathcal{J}) .
$$


Proof: $1 \leftrightarrow 2$ By Theorem 13 , J has an $\mathrm{N}$-equivalence system iff $\mathrm{E}^{\mathrm{m}}$ is an $\mathrm{N}$ equivalence system for J. But $E^{m}$ is an $N$-equivalence system for $\mathcal{J}$ if and only if it satisfies Conditions 2 and 3 of the definition of an $\mathrm{N}$-equivalence system, since it automatically satisfies Condition I, by its definition.

$1 \rightarrow 3$ By Proposition $9 \mathrm{~J}$ is $\mathrm{N}$-protoalgebraic, whence $\Omega^{\mathrm{N}}$ is monotone on theory families.

Suppose, next, that $E$ is an $\mathrm{N}$-equivalence system for $\mathcal{J},\langle F, \alpha\rangle: \mathcal{J}\rangle{ }^{s e} \mathcal{J}$ an $(\mathrm{N}, \mathrm{N})$-logical morphism, with $\mathrm{F}$ surjective, and $\mathrm{T} \in \mathrm{ThFam}(\mathcal{J})$. Then $\alpha^{-1}(T) \in \operatorname{ThFam}(\mathcal{J})$ and, for all $\Sigma \in|\operatorname{Sign}|, \phi, \psi \in \operatorname{SEN}(\Sigma)$, we have

$$
\begin{aligned}
& \langle\phi, \psi\rangle \in \alpha_{\Sigma}^{-1}\left(\Omega_{\mathrm{F}(\Sigma)}^{\mathrm{N}}(\mathrm{T})\right) \\
& \text { iff }\left\langle\alpha_{\Sigma}(\phi), \alpha_{\Sigma}(\psi)\right\rangle \in \Omega_{F(\Sigma)}^{N}(T) \\
& \text { iff }(\forall f)\left(E_{F\left(\Sigma^{\prime}\right)}\left(\operatorname{SEN}(F(f))^{2}\left(\alpha_{\Sigma}(\phi), \alpha_{\Sigma}(\psi)\right)\right) \subseteq T_{F\left(\Sigma^{\prime}\right)}\right) \\
& \text { iff }(\forall f)\left(E_{F\left(\Sigma^{\prime}\right)}\left(\alpha_{\Sigma^{\prime}}^{2}\left(\operatorname{SEN}(f)^{2}(\phi, \psi)\right)\right) \subseteq T_{F\left(\Sigma^{\prime}\right)}\right) \\
& \text { iff }(\forall f)\left(\alpha_{\Sigma^{\prime}}\left(E_{\Sigma^{\prime}}\left(\operatorname{SEN}(f)^{2}(\phi, \psi)\right)\right) \subseteq T_{F\left(\Sigma^{\prime}\right)}\right) \\
& \text { iff }(\forall f)\left(E_{\Sigma^{\prime}}\left(\operatorname{SEN}(f)^{2}(\phi, \psi)\right) \subseteq \alpha_{\Sigma^{\prime}}^{-1}\left(T_{F\left(\Sigma^{\prime}\right)}\right)\right) \\
& \text { iff }\langle\phi, \psi\rangle \in \Omega_{\Sigma}^{N}\left(\alpha^{-1}(\mathrm{~T})\right) \text {. }
\end{aligned}
$$

$3 \rightarrow 4$ Let $\langle\mathrm{F}, \alpha\rangle: \mathcal{J}^{\mathrm{se}}{ }^{\mathrm{se}}$ be an $(\mathrm{N}, \mathrm{N})$-logical morphism, with $\mathrm{F}$ an isomorphism, and $T \in \operatorname{ThFam}(\mathcal{J})$. Let, also, $\mathrm{T}^{\prime}=\mathrm{C}(\alpha(\mathrm{T})) \in \operatorname{ThFam}(\mathcal{J})$. We have that $T \leqslant \alpha^{-1}\left(T^{\prime}\right)$, whence, since $\mathcal{J}$ is $N$-protoalgebraic, $\Omega^{\mathrm{N}}(T) \leqslant$ $\Omega^{N}\left(\alpha^{-1}\left(T^{\prime}\right)\right)$. Therefore, by the hypothesis, $\Omega^{N}(T) \leqslant \alpha^{-1}\left(\Omega^{N}\left(T^{\prime}\right)\right)$, which proves that

$$
\alpha\left(\Omega^{\mathrm{N}}(\mathrm{T})\right) \leqslant \Omega^{\mathrm{N}}\left(\mathrm{T}^{\prime}\right)=\Omega^{\mathrm{N}}(\mathrm{C}(\alpha(\mathrm{T}))) .
$$

Theorem $\mathrm{I} 6$ shows that, if a $\pi$-institution has an $\mathrm{N}$-equivalence system, then its N-Leibniz operator is monotone on theory families and "commutes with inverse translations". Unlike the situation in the sentential logic framework, where these two conditions characterize those logics possessing a system of equivalence formulas, it does not seem to be the case for $\pi$-institutions that Condition I above is equivalent with Condition 3 or Condition 4 . Therefore, it may be appropriate in this case to introduce the following two terms for classes of $\pi$-institutions.

DEFINITION I7 Let $\mathcal{J}=\langle$ Sign, SEN, $\mathrm{C}\rangle$ be a $\pi$-institution, with $\mathrm{N}$ a category of natural transformations on SEN.

- $\mathcal{J}$ is said to be syntactically $\mathrm{N}$-equivalential if there exists an $\mathrm{N}$ equivalence system $E$ for $\mathcal{J}$.

- J is said to be semantically $\mathrm{N}$-equivalential if it is $\mathrm{N}$-protoalgebraic and, for every $(\mathrm{N}, \mathrm{N})$-logical morphism $\langle\mathrm{F}, \alpha\rangle: \mathcal{J} \gamma^{\mathrm{se}}{ }^{\mathrm{J}}$, with $\mathrm{F}$ surjective,

$$
\alpha^{-1}\left(\Omega^{\mathrm{N}}(\mathrm{T})\right)=\Omega^{\mathrm{N}}\left(\alpha^{-1}(\mathrm{~T})\right), \quad \text { for all } \mathrm{T} \in \operatorname{ThFam}(\mathcal{J}) .
$$


With Definition I7, the following illustrates the two-step hierarchy established by Theorem 16 .

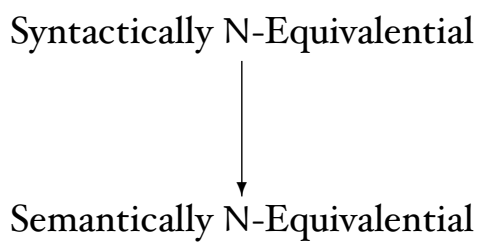

In closing this section, it is now shown that, modulo some cardinality restrictions, syntactic $\mathrm{N}$-equivalentiality implies the continuity of the N-Leibniz operator on theory families.

Given a $\pi$-institution $\mathcal{J}=\langle$ Sign, $S E N, C\rangle$, with $N$ a category of natural transformations on SEN, the N-Leibniz operator $\Omega^{N}$ is said to be $\mu$-continuous on the theory families ThFam $(\mathcal{J})$ of $\mathcal{J}$, for some infinite regular cardinal $\mu$, if, for every $\mu$-directed collection $\left\{T^{i}: i \in I\right\}$ of theory families of $\mathcal{J}$, such that $\bigcup_{i \in I} T^{i}=\left\{\bigcup_{i \in I} T_{\Sigma}^{i}\right\}_{\Sigma \in \mid \text { Sign } \mid}$ is also a theory family of $\mathcal{J}$,

$$
\Omega^{N}\left(\bigcup_{i \in I} T^{i}\right)=\bigcup_{i \in I} \Omega^{N}\left(T^{i}\right) .
$$

THEOREM I8 Let J $=\langle$ Sign, SEN , C $\rangle$ be a $\pi$-institution, such that

$$
\max \left\{|\operatorname{Sign}|, \max _{\Sigma \in|\operatorname{Sign}|}\{\operatorname{Sign}(\Sigma,-)\}\right\}<\mu
$$

for some infinite regular cardinal $\mu$, and $\mathrm{N}$ a category of natural transformations on SEN. If J has an $\mathrm{N}$-equivalence system $\mathrm{E}$, with $|\mathrm{E}|<\mu$, then $\Omega^{\mathrm{N}}$ is $\mu$-continuous on $\operatorname{ThFam}(\mathcal{J})$.

Proof: Suppose that $\mathrm{E}$, with $|\mathrm{E}|<\mu$, is an $\mathrm{N}$-equivalence system for $\mathcal{J}$ and that $\left\{T^{i}: i \in I\right\}$ is a $\mu$-directed collection of theory families of $\mathcal{J}$, such that $\bigcup_{i \in I} T^{i}$ is also a theory family of J. By Theorem 9 J I is N-protoalgebraic, whence $\Omega^{N}$ is monotone on theory families and this immediately yields that $\Omega^{N}\left(T^{i}\right) \leqslant$ $\Omega^{N}\left(\bigcup_{i \in I} T^{i}\right)$, for all $i \in I$, which shows that $\bigcup_{i \in I} \Omega^{N}\left(T^{i}\right) \leqslant \Omega^{N}\left(\bigcup_{i \in I} T^{i}\right)$.

For the reverse inclusion, suppose that $\Sigma \in|\operatorname{Sign}|, \phi, \psi \in \operatorname{SEN}(\Sigma)$, such that $\langle\phi, \psi\rangle \in \Omega_{\Sigma}^{N}\left(\bigcup_{i \in \mathrm{I}} T^{i}\right)$. Hence, we obtain, by Theorem 5 , that $\langle\phi, \psi\rangle \in$ $E_{\Sigma}\left(\bigcup_{i \in I} T^{i}\right)$, i.e., that

$$
(\forall f)\left(E_{\Sigma^{\prime}}\left(\operatorname{SEN}(f)^{2}(\phi, \psi)\right) \subseteq \bigcup_{i \in I} T_{\Sigma^{\prime}}^{i}\right) .
$$

Since $|E|<\mu$ and Inequality (3.) holds, there exists, by the $\mu$-directedness of $\left\{T^{i}: i \in I\right\}$, an $i \in I$, such that

$$
(\forall f)\left(E_{\Sigma^{\prime}}\left(\operatorname{SEN}(f)^{2}(\phi, \psi)\right) \subseteq T_{\Sigma^{\prime}}^{i}\right) .
$$


Therefore, $\langle\phi, \psi\rangle \in E_{\Sigma}\left(T^{i}\right)=\Omega_{\Sigma}^{N}\left(T^{i}\right)$ and, hence, $\Omega_{\Sigma}^{N}\left(\bigcup_{i \in I} T^{i}\right) \subseteq$ $\bigcup_{i \in I} \Omega_{\Sigma}^{N}\left(T^{i}\right) . \quad \Sigma \in \mid$ Sign| being arbitrary, this shows that $\Omega^{N}\left(\bigcup_{i \in I} T^{i}\right) \leqslant$ $\bigcup_{i \in I} \Omega^{N}\left(T^{i}\right)$ and, therefore, $\Omega^{N}\left(\bigcup_{i \in I} T^{i}\right)=\bigcup_{i \in I} \Omega^{N}\left(T^{i}\right)$. Thus $\Omega^{N}$ is indeed $\mu$-continuous on the theory families of $\mathcal{J}$.

Combining Theorem $\mathrm{I} 8$ with Theorem $\mathrm{IO}$ we immediately obtain THEOREM I9 Let J $=\langle$ Sign, SEN,$C\rangle$ be a $\pi$-institution, such that

$$
\max \left\{|\operatorname{Sign}|, \max _{\Sigma \in|\operatorname{Sign}|}\{\operatorname{Sign}(\Sigma,-)\}\right\}<\mu
$$

for some infinite regular cardinal $\mu$, and $\mathrm{N}$ a category of natural transformations on SEN. Suppose that $J^{\prime}=\left\langle\mathrm{Sign}^{\prime}, \mathrm{SEN}^{\prime}, \mathrm{C}^{\prime}\right\rangle$, with $\mathrm{N}^{\prime}$ a category of natural transformations on $\mathrm{SEN}^{\prime}$, is an $\left(\mathrm{N}, \mathrm{N}^{\prime}\right)$-model of $\mathrm{J}$ via a surjective $\left(\mathrm{N}, \mathrm{N}^{\prime}\right)$-logical morphism $\langle\mathrm{F}, \alpha\rangle: \mathcal{J}_{\rangle}{ }^{\mathrm{se}^{\prime} \mathcal{J}^{\prime}}$. If J has an $\mathrm{N}$-equivalence system $\mathrm{E}$, with $|\mathrm{E}|<\mu$, then $\Omega^{\mathrm{N}^{\prime}}$ is $\mu$ continuous on $\operatorname{ThFam}\left(\mathcal{J}^{\prime}\right)$.

\section{N-MATRIX SYSTEMS}

Given a functor SEN : Sign $\rightarrow$ Set, with $N$ a category of natural transformations on SEN, an N-matrix system $\left\langle\left\langle\mathrm{SEN}^{\prime},\langle\mathrm{F}, \alpha\rangle\right\rangle, \mathrm{T}^{\prime}\right\rangle$ for $\mathrm{SEN}$ consists of a functor $\mathrm{SEN}^{\prime}: \mathrm{Sign}^{\prime} \rightarrow$ Set, with $\mathrm{N}^{\prime}$ a category of natural transformations on $\mathrm{SEN}^{\prime}$, and a surjective $\left(\mathrm{N}, \mathrm{N}^{\prime}\right)$-epimorphic translation $\langle\mathrm{F}, \alpha\rangle: \mathrm{SEN} \rightarrow{ }^{\text {se }} \mathrm{SEN}^{\prime}$, together with an axiom family $\mathrm{T}^{\prime}$ of $\mathrm{SEN}^{\prime}$. Given a class $\mathrm{K}$ of matrix systems for SEN, $K$ induces a closure system $C^{K}$ on SEN, defined, for all $\Sigma \in \mid$ Sign|, $\Phi \cup\{\phi\} \subseteq \operatorname{SEN}(\Sigma)$, by

$$
\begin{array}{r}
\phi \in \mathrm{C}_{\Sigma}^{\mathrm{K}}(\Phi) \text { iff for all }\left\langle\left\langle\mathrm{SEN}^{\prime},\langle\mathrm{F}, \alpha\rangle\right\rangle, \mathrm{T}^{\prime}\right\rangle \in \mathrm{K}, \Sigma^{\prime} \in|\operatorname{Sign}|, f \in \operatorname{Sign}\left(\Sigma, \Sigma^{\prime}\right), \\
\alpha_{\Sigma^{\prime}}(\operatorname{SEN}(f)(\Phi)) \subseteq \mathrm{T}_{\Sigma^{\prime}}^{\prime} \text { implies } \alpha_{\Sigma^{\prime}}(\operatorname{SEN}(\mathrm{f})(\phi)) \in \mathrm{T}_{\Sigma^{\prime}}^{\prime} .
\end{array}
$$

The last implication will be usually abbreviated in the form

$$
(\forall f)\left(\alpha_{\Sigma^{\prime}}(\operatorname{SEN}(f)(\Phi)) \subseteq \mathrm{T}_{\Sigma^{\prime}}^{\prime} \Longrightarrow \alpha_{\Sigma^{\prime}}(\operatorname{SEN}(f)(\phi)) \in \mathrm{T}_{\Sigma^{\prime}}^{\prime}\right) .
$$

LEMMA 20 Given a functor SEN : Sign $\rightarrow$ Set, with N a category of natural transformations on $\mathrm{SEN}$, and a class $\mathrm{K}$ of matrix systems for $\mathrm{SEN}, \mathrm{C}^{\mathrm{K}}$ is a closure system on SEN.

Proof: Suppose that $\Sigma^{\prime} \in|\operatorname{Sign}|, f \in \operatorname{Sign}\left(\Sigma, \Sigma^{\prime}\right), \Phi \subseteq \operatorname{SEN}(\Sigma)$ and $\phi \in \Phi$. Then we have, for all $\left\langle\left\langle\mathrm{SEN}^{\prime},\langle\mathrm{F}, \alpha\rangle\right\rangle, \mathrm{T}^{\prime}\right\rangle \in \mathrm{K}, \alpha_{\Sigma^{\prime}}(\mathrm{SEN}(\mathrm{f})(\Phi)) \subseteq \mathrm{T}_{\Sigma^{\prime}}^{\prime}$ implies that $\alpha_{\Sigma^{\prime}}(\operatorname{SEN}(f)(\phi)) \in \mathrm{T}_{\Sigma \prime}^{\prime}$. Therefore $\phi \in \mathrm{C}_{\Sigma}^{\mathrm{K}}(\Phi)$ and $\mathrm{C}^{\mathrm{K}}$ is inflationary.

If $\Sigma \in|\operatorname{Sign}|$ and $\Phi \subseteq \Psi \subseteq \operatorname{SEN}(\Sigma)$, then, if $\phi \in \mathrm{C}_{\Sigma}^{\mathrm{K}}(\Phi)$, we have, for all $\left\langle\left\langle\mathrm{SEN}^{\prime},\langle\mathrm{F}, \alpha\rangle\right\rangle, \mathrm{T}^{\prime}\right\rangle \in \mathrm{K}$, that

$$
(\forall f)\left(\alpha_{\Sigma^{\prime}}(\operatorname{SEN}(f)(\Phi)) \subseteq T_{\Sigma^{\prime}}^{\prime} \quad \text { implies } \quad \alpha_{\Sigma^{\prime}}(\operatorname{SEN}(f)(\phi)) \in T_{\Sigma^{\prime}}^{\prime}\right) .
$$


Therefore, for all $\Sigma^{\prime} \in|\operatorname{Sign}|, f \in \operatorname{Sign}\left(\Sigma, \Sigma^{\prime}\right)$, we have $\alpha_{\Sigma^{\prime}}(\operatorname{SEN}(f)(\Psi)) \subseteq$ $\mathrm{T}_{\Sigma^{\prime}}^{\prime}$ implies $\alpha_{\Sigma^{\prime}}(\operatorname{SEN}(f)(\Phi)) \subseteq \mathrm{T}_{\Sigma^{\prime}}^{\prime}$, which gives $\alpha_{\Sigma^{\prime}}(\mathrm{SEN}(f)(\phi)) \in \mathrm{T}_{\Sigma^{\prime}}^{\prime}$, and, hence, $\phi \in C_{\Sigma}^{K}(\Psi)$. Thus, $C^{K}$ is also monotone.

Now suppose that $\Sigma \in|\operatorname{Sign}|, \Phi \cup\{\phi\} \subseteq \operatorname{SEN}(\Sigma)$, such that $\phi \in C_{\Sigma}^{K}\left(C_{\Sigma}^{K}(\Phi)\right)$. This means that, for all $\left\langle\left\langle\operatorname{SEN}^{\prime},\langle F, \alpha\rangle\right\rangle, T^{\prime}\right\rangle \in K$,

$$
(\forall f)\left(\alpha_{\Sigma^{\prime}}\left(\operatorname{SEN}(f)\left(C_{\Sigma}^{K}(\Phi)\right)\right) \subseteq T_{\Sigma^{\prime}}^{\prime} \quad \text { implies } \quad \alpha_{\Sigma^{\prime}}(\operatorname{SEN}(f)(\phi)) \in T_{\Sigma^{\prime}}^{\prime}\right) .
$$

But then, we have, for all $\Sigma^{\prime} \in|\operatorname{Sign}|, f \in \operatorname{Sign}\left(\Sigma, \Sigma^{\prime}\right), \alpha_{\Sigma^{\prime}}(\operatorname{SEN}(f)(\Phi)) \subseteq \mathrm{T}_{\Sigma^{\prime}}^{\prime}$ implies, by the definition of $C^{K}$, that $\alpha_{\Sigma^{\prime}}\left(\operatorname{SEN}(f)\left(C_{\Sigma}^{K}(\Phi)\right)\right) \subseteq T_{\Sigma^{\prime}}^{\prime}$, which yields that $\alpha_{\Sigma^{\prime}}(\operatorname{SEN}(f)(\phi)) \in \mathrm{T}_{\Sigma^{\prime}}^{\prime}$, whence $\phi \in \mathrm{C}_{\Sigma}^{\mathrm{K}}(\Phi)$ and $\mathrm{C}^{\mathrm{K}}$ is idempotent.

Finally, suppose $\Sigma_{1}, \Sigma_{2} \in|\operatorname{Sign}|, f \in \operatorname{Sign}\left(\Sigma_{1}, \Sigma_{2}\right)$ and $\Phi \cup\{\phi\} \subseteq$ $\operatorname{SEN}\left(\Sigma_{1}\right)$, such that $\phi \in \mathrm{C}_{\Sigma_{1}}^{\mathrm{K}}(\Phi)$. Thus, for all $\left\langle\left\langle\mathrm{SEN}^{\prime},\langle\mathrm{F}, \alpha\rangle\right\rangle, \mathrm{T}^{\prime}\right\rangle \in \mathrm{K}$,

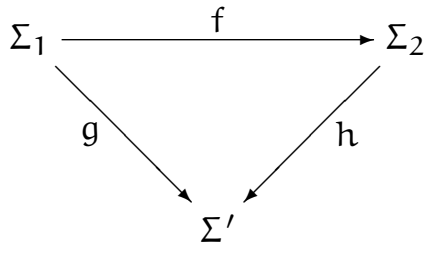

$(\forall \mathrm{g})\left(\alpha_{\Sigma^{\prime}}(\operatorname{SEN}(\mathrm{g})(\Phi)) \subseteq \mathrm{T}_{\Sigma^{\prime}}^{\prime} \quad\right.$ implies $\left.\quad \alpha_{\Sigma^{\prime}}(\operatorname{SEN}(\mathrm{g})(\phi)) \in \mathrm{T}_{\Sigma^{\prime}}^{\prime}\right)$.

Hence, we have, for all $\Sigma^{\prime} \in|\operatorname{Sign}|, h \in \operatorname{Sign}\left(\Sigma_{2}, \Sigma^{\prime}\right)$,

$$
\alpha_{\Sigma^{\prime}}(\operatorname{SEN}(h)(\operatorname{SEN}(f)(\Phi))) \subseteq \mathrm{T}_{\Sigma^{\prime}}^{\prime} \text { iff } \alpha_{\Sigma^{\prime}}(\operatorname{SEN}(h f)(\Phi)) \subseteq \mathrm{T}_{\Sigma^{\prime}}^{\prime}
$$

implies $\alpha_{\Sigma^{\prime}}(\operatorname{SEN}(h f)(\phi)) \in \mathrm{T}_{\Sigma^{\prime}}^{\prime}$ iff $\alpha_{\Sigma^{\prime}}(\operatorname{SEN}(h)(\operatorname{SEN}(f)(\phi))) \in \mathrm{T}_{\Sigma^{\prime}}^{\prime}$, whence $\operatorname{SEN}(f)(\phi) \in C_{\Sigma_{2}}^{K}(\operatorname{SEN}(f)(\Phi))$, and $C^{K}$ is also structural.

Given a $\pi$-institution $\mathcal{J}=\langle$ Sign, $\operatorname{SEN}, \mathrm{C}\rangle$, with $\mathrm{N}$ a category of natural transformations on SEN, an N-matrix system $\left\langle\left\langle\mathrm{SEN}^{\prime},\langle\mathrm{F}, \alpha\rangle\right\rangle, \mathrm{T}^{\prime}\right\rangle$ for SEN is said to be an $N$-matrix system for $\mathcal{J}$ if $\left.C \leqslant C^{\{}\left\langle\left\langle\operatorname{SEN}^{\prime},\langle F, \alpha\rangle\right\rangle, T^{\prime}\right\rangle\right\}$. A class $K$ of $\mathrm{N}$-matrix systems for a $\pi$-institution $\mathcal{J}=\langle\mathrm{Sign}, \mathrm{SEN}, \mathrm{C}\rangle$ is said to be strongly adequate for $\mathcal{J}$ if and only if $C=C^{K}$.

Given a $\pi$-institution $\mathcal{J}=\langle\operatorname{Sign}, \mathrm{SEN}, \mathrm{C}\rangle$, with $\mathrm{N}$ a category of natural transformations on SEN, the $N$-Lindenbaum bundle for $\mathcal{J}$ is the class $\mathrm{L}_{\mathcal{J}}^{N}$ of all matrix systems of the form $\left\langle\left\langle\operatorname{SEN},\left\langle\mathrm{I}_{\mathrm{Sign}}, l\right\rangle\right\rangle, T\right\rangle$, with $T \in \operatorname{ThFam}(\mathcal{J})$, where by $\left\langle\mathrm{I}_{\text {Sign }}, l\right\rangle:$ SEN $\rightarrow{ }^{\text {se }}$ SEN is denoted the identity $(N, N)$-epimorphic translation. By $\mathrm{MtSys}^{\mathrm{N}}(\mathcal{J})$ is denoted the class of all $\mathrm{N}$-matrix systems for $\mathrm{J}$.

The following lemma characterizes those $\mathrm{N}$-matrix systems for SEN that are $\mathrm{N}$-matrix systems for a $\pi$-institution $\mathcal{J}=\langle$ Sign, $\mathrm{SEN}, \mathrm{C}\rangle$.

LEMMA 2I Let $\mathrm{J}=\langle\mathrm{Sign}, \mathrm{SEN}, \mathrm{C}\rangle$ be a $\pi$-institution and $\mathrm{N}$ a category of natural transformations on SEN. The N-matrix system $\left\langle\left\langle\mathrm{SEN}^{\prime},\langle\mathrm{F}, \alpha\rangle\right\rangle, \mathrm{T}^{\prime}\right\rangle$ for $\mathrm{SEN}$ is an $\mathrm{N}$-matrix system for $\mathcal{J}$ if and only if, for all $\Sigma \in|\mathrm{Sign}|, \Phi \cup\{\phi\} \subseteq \mathrm{SEN}(\Sigma)$,

$$
\phi \in \mathrm{C}_{\Sigma}(\Phi)
$$


implies for all $\Sigma^{\prime} \in|\operatorname{Sign}|, \mathrm{f} \in \operatorname{Sign}\left(\Sigma, \Sigma^{\prime}\right)$

$$
\alpha_{\Sigma^{\prime}}(\operatorname{SEN}(f)(\Phi)) \subseteq \mathrm{T}_{\Sigma^{\prime}}^{\prime} \text { implies } \alpha_{\Sigma^{\prime}}(\operatorname{SEN}(f)(\phi)) \in \mathrm{T}_{\Sigma^{\prime}}^{\prime} .
$$

Proof: $\left\langle\left\langle\mathrm{SEN}^{\prime},\langle\mathrm{F}, \alpha\rangle\right\rangle, \mathrm{T}^{\prime}\right\rangle$ is an $\mathrm{N}$-matrix system for $\mathcal{J}$ if and only if $\mathrm{C} \leqslant$ $\left.\mathrm{C}^{\{}\left\langle\left\langle\mathrm{SEN}^{\prime},\langle\mathrm{F}, \alpha\rangle\right\rangle, \mathrm{T}^{\prime}\right\rangle\right\}$ if and only if, for all $\Sigma \in|\operatorname{Sign}|, \Phi \cup\{\phi\} \subseteq \operatorname{SEN}(\Sigma)$,

$$
\phi \in \mathrm{C}_{\Sigma}(\Phi) \quad \text { implies } \quad \phi \in \mathrm{C}_{\Sigma}^{\left\{\left\langle\left\langle\operatorname{SEN}^{\prime},\langle\mathrm{F}, \alpha\rangle\right\rangle, \mathrm{T}^{\prime}\right\rangle\right\}}(\Phi)
$$

if and only if, for all $\Sigma \in|\operatorname{Sign}|, \Phi \cup\{\phi\} \subseteq \operatorname{SEN}(\Sigma), \phi \in \mathrm{C}_{\Sigma}(\Phi)$ implies, for all $\Sigma^{\prime} \in|\operatorname{Sign}|, f \in \operatorname{Sign}\left(\Sigma, \Sigma^{\prime}\right)$,

$$
\alpha_{\Sigma^{\prime}}(\operatorname{SEN}(f)(\Phi)) \subseteq \mathrm{T}_{\Sigma^{\prime}}^{\prime} \text { implies } \alpha_{\Sigma^{\prime}}(\operatorname{SEN}(f)(\phi)) \in \mathrm{T}_{\Sigma^{\prime}}^{\prime}
$$

It is not very difficult to see that both $\mathrm{L}_{\mathcal{J}}^{\mathrm{N}}$ and $\mathrm{MtSys}^{\mathrm{N}}(\mathcal{J})$ are strongly adequate classes of $\mathrm{N}$-matrix systems for $\mathrm{J}$.

PROPOSITION 22 Given a $\pi$-institution $\mathcal{J}=\langle$ Sign, $\mathrm{SEN}, \mathrm{C}\rangle$, with $\mathrm{N}$ a category of natural transformations on $\mathrm{SEN}$, both its $\mathrm{N}$-Lindenbaum bundle $\mathrm{L}_{\mathcal{J}}^{\mathrm{N}}$ and the collection of all $\mathrm{N}$-matrix systems $\mathrm{MtSys}{ }^{\mathrm{N}}(\mathcal{J})$ are strongly adequate for $\mathrm{J}$.

We revisit now Theorem $\mathrm{I}$ in the language of $\mathrm{N}$-matrix systems. We also prove some further results paralleling some of the matrix preservation theorems for equivalential sentential logics (see [6] and [7]).

Let $\mathcal{J}=\langle$ Sign, SEN,$C\rangle$ be a $\pi$-institution, $\mathrm{N}$ a category of natural transformations on SEN and E a subcollection of natural transformations $\mathrm{SEN}^{2} \rightarrow$ SEN in $N$. The $N$-matrix system $\left\langle\left\langle\mathrm{SEN}^{\prime},\langle F, \alpha\rangle\right\rangle, \mathrm{T}^{\prime}\right\rangle$ for $\mathcal{J}$ is said to have the analytical congruence property relative to $E$ or, more simply, to be $E-$ analytical if $\Omega^{N^{\prime}}\left(T^{\prime}\right)=E^{\prime}\left(T^{\prime}\right)$, where $E^{\prime}$ is the collection of natural transformations in $\mathrm{N}^{\prime}$ corresponding to $E$ via the $\left(N, N^{\prime}\right)$-epimorphic property. $A$ class $\mathrm{K}$ of $\mathrm{N}$-matrix systems for $\mathcal{J}$ is said to be $\mathrm{E}$-analytical if every $\mathrm{N}$-matrix system in $\mathrm{K}$ is E-analytical.

Theorem $\Pi$ has the following translation when it is stated in the language of the $\mathrm{N}$-matrix systems for a $\pi$-institution $\mathcal{J}$.

THEOREM 23 (second version of theorem II) Let $\mathcal{J}=\langle$ Sign, SEN, C be a $\pi$-institution, $\mathrm{N}$ a category of natural transformations on $\mathrm{SEN}$ and $\mathrm{E}$ a subcollection of natural transformations $\mathrm{SEN}^{2} \rightarrow \mathrm{SEN}$ in $\mathrm{N}$. E is an $\mathrm{N}$-equivalence system for $\mathrm{J}$ if and only if $\mathrm{MtSys}^{\mathrm{N}}(\mathrm{J})$ is $\mathrm{E}$-analytical.

Let $\mathcal{J}=\langle$ Sign, SEN,$C\rangle$ be a $\pi$-institution and $N$ a category of natural transformations on SEN. Given two N-matrix systems $\left\langle\left\langle\mathrm{SEN}^{\prime},\left\langle\mathrm{F}^{\prime}, \alpha^{\prime}\right\rangle\right\rangle, \mathrm{T}^{\prime}\right\rangle$ and $\left\langle\left\langle\mathrm{SEN}^{\prime \prime},\left\langle\mathrm{F}^{\prime \prime}, \alpha^{\prime \prime}\right\rangle\right\rangle, \mathrm{T}^{\prime \prime}\right\rangle$ for $\mathcal{J}$, an $\left(\mathrm{N}^{\prime}, \mathrm{N}^{\prime \prime}\right)$-epimorphic translation $\langle\mathrm{F}, \alpha\rangle$ : SEN $^{\prime} \rightarrow{ }^{\text {se }}$ SEN $^{\prime \prime}$ is said to be a strict translation

$$
\langle\mathrm{F}, \alpha\rangle:\left\langle\left\langle\mathrm{SEN}^{\prime},\left\langle\mathrm{F}^{\prime}, \alpha^{\prime}\right\rangle\right\rangle, \mathrm{T}^{\prime}\right\rangle \rightarrow^{\text {se }}\left\langle\left\langle\mathrm{SEN}^{\prime \prime},\left\langle\mathrm{F}^{\prime \prime}, \alpha^{\prime \prime}\right\rangle\right\rangle, \mathrm{T}^{\prime \prime}\right\rangle
$$

if: 
- the following triangle commutes and

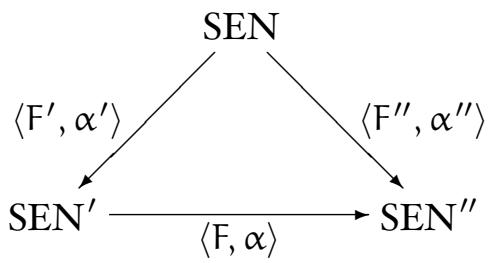

- for all $\Sigma \in|\operatorname{Sign}|, \phi \in \operatorname{SEN}(\Sigma)$,

$$
\alpha_{\Sigma}^{\prime}(\phi) \in \mathrm{T}_{\mathrm{F}^{\prime}(\Sigma)}^{\prime} \quad \text { iff } \quad \alpha_{\Sigma}^{\prime \prime}(\phi) \in \mathrm{T}_{\mathrm{F}^{\prime \prime}(\Sigma)}^{\prime \prime} .
$$

PROPOSITION 24 Let $\mathcal{J}=\langle$ Sign, SEN, $\mathrm{C}\rangle$ be a $\pi$-institution and $\mathrm{N}$ a category of natural transformations on SEN. Let

$$
\langle\mathrm{F}, \alpha\rangle:\left\langle\left\langle\mathrm{SEN}^{\prime},\left\langle\mathrm{F}^{\prime}, \alpha^{\prime}\right\rangle\right\rangle, \mathrm{T}^{\prime}\right\rangle \rightarrow^{\text {se }}\left\langle\left\langle\mathrm{SEN}^{\prime \prime},\left\langle\mathrm{F}^{\prime \prime}, \alpha^{\prime \prime}\right\rangle\right\rangle, \mathrm{T}^{\prime \prime}\right\rangle
$$

be a strict translation from the $\mathrm{N}$-matrix system $\left\langle\left\langle\mathrm{SEN}^{\prime},\left\langle\mathrm{F}^{\prime}, \alpha^{\prime}\right\rangle\right\rangle, \mathrm{T}^{\prime}\right\rangle$ for $\mathcal{J}$ onto the $\mathrm{N}$-matrix system $\left\langle\left\langle\mathrm{SEN}^{\prime \prime},\left\langle\mathrm{F}^{\prime \prime}, \alpha^{\prime \prime}\right\rangle\right\rangle, \mathrm{T}^{\prime \prime}\right\rangle$ for J. Then $\left\langle\left\langle\mathrm{SEN}^{\prime},\left\langle\mathrm{F}^{\prime}, \alpha^{\prime}\right\rangle\right\rangle, \mathrm{T}^{\prime}\right\rangle$ is $\mathrm{E}-$ analytical iff $\left\langle\left\langle\mathrm{SEN}^{\prime \prime},\left\langle\mathrm{F}^{\prime \prime}, \alpha^{\prime \prime}\right\rangle\right\rangle, \mathrm{T}^{\prime \prime}\right\rangle$ is $\mathrm{E}$-analytical.

Proof: It suffices to show that $\Omega^{N^{\prime}}\left(T^{\prime}\right)=E^{\prime}\left(T^{\prime}\right)$ if and only if $\Omega^{N^{\prime \prime}}\left(T^{\prime \prime}\right)=$ $E^{\prime \prime}\left(T^{\prime \prime}\right)$. To do this, it is shown, first, that, for all $\Sigma \in\left|\mathrm{Sign}^{\prime}\right|$,

$$
\alpha_{\Sigma}\left(E_{\Sigma}^{\prime}\left(\alpha^{-1}\left(T^{\prime \prime}\right)\right)\right)=E_{F(\Sigma)}^{\prime \prime}\left(T^{\prime \prime}\right),
$$

i.e., that for all $\Sigma \in\left|\operatorname{Sign}^{\prime}\right|, \phi, \psi \in \operatorname{SEN}\left(\Sigma^{\prime}\right)$,

$$
\langle\phi, \psi\rangle \in \mathrm{E}_{\Sigma}^{\prime}\left(\alpha^{-1}\left(\mathrm{~T}^{\prime \prime}\right)\right) \quad \text { iff } \quad\left\langle\alpha_{\Sigma}(\phi), \alpha_{\Sigma}(\psi)\right\rangle \in \mathrm{E}_{\mathrm{F}(\Sigma)}^{\prime \prime}\left(\mathrm{T}^{\prime \prime}\right) .
$$

We have

$$
\begin{aligned}
\langle\phi, \psi\rangle \in E_{\Sigma}^{\prime}\left(\alpha^{-1}\left(T^{\prime \prime}\right)\right) \\
\text { iff } \quad(\forall f)\left(E_{\Sigma^{\prime}}^{\prime}\left(\operatorname{SEN}^{\prime}(f)^{2}(\phi, \psi)\right) \subseteq \alpha_{\Sigma^{\prime}}^{-1}\left(T_{F\left(\Sigma^{\prime}\right)}^{\prime \prime}\right)\right) \\
\text { iff } \quad(\forall f)\left(\alpha_{\Sigma^{\prime}}\left(E_{\Sigma^{\prime}}^{\prime}\left(\operatorname{SEN}^{\prime}(f)^{2}(\phi, \psi)\right)\right) \subseteq T_{F\left(\Sigma^{\prime}\right)}^{\prime \prime}\right) \\
\text { iff } \quad(\forall f)\left(E_{F\left(\Sigma^{\prime}\right)}^{\prime \prime}\left(\alpha_{\Sigma^{\prime}}^{2}\left(\operatorname{SEN}^{\prime}(f)^{2}(\phi, \psi)\right)\right) \subseteq \mathrm{T}_{F}^{\prime \prime}\left(\Sigma^{\prime}\right)\right) \\
\text { iff } \quad(\forall f)\left(E_{F\left(\Sigma^{\prime}\right)}^{\prime \prime}\left(\operatorname{SEN}^{\prime \prime}(F(f))^{2}\left(\alpha_{\Sigma}(\phi), \alpha_{\Sigma}(\psi)\right)\right) \subseteq T_{F^{\prime}\left(\Sigma^{\prime}\right)}^{\prime \prime}\right) \\
\text { iff }\left\langle\alpha_{\Sigma}(\phi), \alpha_{\Sigma}(\psi)\right\rangle \in E_{F(\Sigma)}^{\prime \prime}\left(T^{\prime \prime}\right) .
\end{aligned}
$$

Suppose, now, that $\Omega^{N^{\prime}}\left(T^{\prime}\right)=E^{\prime}\left(T^{\prime}\right)$. Then we have, for all $\Sigma \in\left|\operatorname{Sign}^{\prime}\right|$, $\phi, \psi \in \operatorname{SEN}^{\prime}(\Sigma)$,

$$
\begin{aligned}
& \left\langle\alpha_{\Sigma}(\phi), \alpha_{\Sigma}(\psi)\right\rangle \in \Omega_{\mathrm{F}(\Sigma)}^{\mathrm{N}^{\prime \prime}}\left(\mathrm{T}^{\prime \prime}\right) \\
& \text { iff }\langle\phi, \psi\rangle \in \alpha_{\Sigma}^{-1}\left(\Omega_{\mathrm{F}(\Sigma)}^{\mathrm{N}^{\prime \prime}}\left(\mathrm{T}^{\prime \prime}\right)\right) \\
& \text { iff }\langle\phi, \psi\rangle \in \Omega_{\Sigma}^{\mathrm{N}^{\prime}}\left(\alpha^{-1}\left(\mathrm{~T}^{\prime \prime}\right)\right) \quad \text { (by Lemma 5.2I of [27]) } \\
& \text { iff }\langle\phi, \psi\rangle \in \mathrm{E}_{\Sigma}^{\prime}\left(\alpha^{-1}\left(\mathrm{~T}^{\prime \prime}\right)\right) \quad \text { (by the hypothesis) } \\
& \text { iff }\left\langle\alpha_{\Sigma}(\phi), \alpha_{\Sigma}(\psi)\right\rangle \in \mathrm{E}_{\mathrm{F}(\Sigma)}^{\prime \prime}\left(\mathrm{T}^{\prime \prime}\right) \quad \text { (by the Equiv. (4)). }
\end{aligned}
$$


Since $\langle F, \alpha\rangle$ is surjective, we obtain that $\Omega^{N^{\prime \prime}}\left(T^{\prime \prime}\right)=E^{\prime \prime}\left(T^{\prime \prime}\right)$.

Suppose, conversely, that $\Omega^{N^{\prime \prime}}\left(T^{\prime \prime}\right)=E^{\prime \prime}\left(T^{\prime \prime}\right)$. Then we have, for all $\Sigma \in$ $\left|\operatorname{Sign}^{\prime}\right|, \phi, \psi \in \operatorname{SEN}^{\prime}(\Sigma)$,

$$
\begin{aligned}
&\langle\phi, \psi\rangle \in \Omega_{\Sigma}^{N^{\prime}}\left(\mathrm{T}^{\prime}\right) \quad \text { iff }\langle\phi, \psi\rangle \in \Omega_{\Sigma}^{N^{\prime}}\left(\alpha^{-1}\left(\mathrm{~T}^{\prime \prime}\right)\right) \\
& \text { iff }\langle\phi, \psi\rangle \in \alpha_{\Sigma}^{-1}\left(\Omega_{\mathrm{F}(\Sigma)}^{N^{\prime \prime}}\left(\mathrm{T}^{\prime \prime}\right)\right) \text { (by Lemma 5.2I of [27]) } \\
& \text { iff }\left\langle\alpha_{\Sigma}(\phi), \alpha_{\Sigma}(\psi)\right\rangle \in \Omega_{\mathrm{F}(\Sigma)}^{\mathrm{N}^{\prime \prime}}\left(\mathrm{T}^{\prime \prime}\right) \\
& \text { iff }\left\langle\alpha_{\Sigma}(\phi), \alpha_{\Sigma}(\psi)\right\rangle \in \mathrm{E}_{\mathrm{F}}^{\prime \prime}\left(\mathrm{T}^{\prime \prime}\right) \text { (by the hypothesis) } \\
& \text { iff }\langle\phi, \psi\rangle \in \mathrm{E}_{\Sigma}^{\prime}\left(\alpha^{-1}\left(\mathrm{~T}^{\prime \prime}\right)\right) \quad \text { (by the Equivalence [4]) } \\
& \text { iff }\langle\phi, \psi\rangle \in \mathrm{E}_{\Sigma}^{\prime}\left(\mathrm{T}^{\prime}\right) .
\end{aligned}
$$

\section{ACKNOWLEDGEMENTS}

Thanks to Don Pigozzi and Charles Wells for encouragement and support. Thanks also to Janusz Czelakowski for developing the theory of equivalential logics and for writing the excellent book Protoalgebraic Logics, that systematized with efficiency and elegance the body of work available until recently in the area of abstract algebraic logic.

\section{REFERENCES}

[I] Barr, M., and Wells, C., Category Theory for Computing Science, Third Edition, Les Publications CRM, Montréal I999.

[2] Blok, W.J., and Pigozzi, D., Protoalgebraic Logics, Studia Logica, Vol. 45 (I986), pp. 337-369

[3] Blok, W.J., and Pigozzi, D., Algebraizable Logics, Memoirs of the American Mathematical Society, Vol. 77, No. 396 (I989)

[4] Blok, W.J., and Pigozzi, D., Algebraic Semantics for Universal Horn Logic Without Equality, in Universal Algebra and Quasigroup Theory, A. Romanowska and J.D.H. Smith, Eds., Heldermann Verlag, Berlin 1992

[5] Borceux, F., Handbook of Categorical Algebra, Encyclopedia of Mathematics and its Applications, Vol. 50, Cambridge University Press, Cambridge, U.K., I994.

[6] Czelakowski, J., Equivalential Logics I,II, Studia Logica, Vol. 4 O (I98I), pp. 227-236, 355-372

[7] Czelakowski, J., Protoalgebraic Logics, Kluwer Academic Publishers, Dordtrecht 200I

[8] Czelakowski, J., and Jansana, R., Weakly Algebraizable Logics, Journal of Symbolic Logic, Vol. 65, No. 2 (2000), pp. 64I-668 
[9] Fiadeiro, J., and Sernadas, A., Structuring Theories on Consequence, in Recent Trends in Data Type Specification, Donald Sannella and Andrzej Tarlecki, Eds., Lecture Notes in Computer Science, Vol. 332, Springer-Verlag, New York 1988, pp. 44-72

[Io] Font, J.M., and Jansana, R., A General Algebraic Semantics for Sentential Logics, Lecture Notes in Logic, Vol. 7 (1996), Springer-Verlag, Berlin Heidelberg 1996

[II] Font, J.M., Jansana, R., and Pigozzi, D., A Survey of Abstract Algebraic Logic, Studia Logica, Vol. 74, No. I/2 (2003), pp. 13-97

[12] Goguen, J.A., and Burstall, R.M., Introducing Institutions, in Proceedings of the Logic of Programming Workshop, E. Clarke and D. Kozen, Eds., Lecture Notes in Computer Science, Vol. 164, Springer-Verlag, New York I984, pp.22I-256

[13] Goguen, J.A., and Burstall, R.M., Institutions: Abstract Model Theory for Specification and Programming, Journal of the Association for Computing Machinery, Vol. 39, No. I (1992), pp. 95-I46

[14] Herrmann, B., Equivalential Logics and Definability of Truth, Dissertation, Freie Universitat Berlin, Berlin 1993

[15] Herrmann, B., Equivalential and Algebraizable Logics, Studia Logica, Vol. 57 (1996), pp. 419-436

[16] Herrmann, B., Characterizing Equivalential and Algebraizable Logics by the Leibniz Operator, Studia Logica, Vol. 58 (1997), pp. 305-323

[17] Mac Lane, S., Categories for the Working Mathematician, Springer-Verlag, I97I.

[18] Prucnal, T., and Wroński, A., An algebraic characterization of the notion of structural completeness, Bulletin of the Section of Logic, Vol. 3 (I974), pp. $30-33$

[19] Voutsadakis, G., Categorical Abstract Algebraic Logic: Equivalent Institutions, Studia Logica, Vol. 74 (2003), No. I/2, pp. 275-3II

[20] Voutsadakis, G., Categorical Abstract Algebraic Logic: Algebraizable Institutions, Applied Categorical Structures, Vol. IO (2002), No. 6, pp. 531-568

[2I] Voutsadakis, G., Categorical Abstract Algebraic Logic: Tarski Congruence Systems, Logical Morphisms and Logical 2uotients, Submitted to the Annals of Pure and Applied Logic, Preprint available at http://voutsadakis. com/RESEARCH/papers.html 
[22] Voutsadakis, G., Categorical Abstract Algebraic Logic: Models of $\pi$-Institutions, Notre Dame Journal of Formal Logic, Vol. 46, No. 4 (2005), pp. 439-460

[23] Voutsadakis, G., Categorical Abstract Algebraic Logic: Generalized Tarski Congruence Systems, Preprint available at http://www . voutsadakis.com/ RESEARCH/papers.html

[24] Voutsadakis, G., Categorical Abstract Algebraic Logic: (J, N)-Algebraic Systems, Applied Categorical Structures, Vol. I3, No. 3 (2005), pp. 265-280

[25] Voutsadakis, G., Categorical Abstract Algebraic Logic: Gentzen $\pi$-Institutions, Scientiae Mathematicae Japonicae, e-2007, 407-422

[26] Voutsadakis, G., Categorical Abstract Algebraic Logic: Full Models, Frege Systems and Metalogical properties, Reports on Mathematical Logic, Vol. 4I (2006), pp. 3I-62

[27] Voutsadakis, G., Categorical Abstract Algebraic Logic: Prealgebraicity and Protoalgebraicity, Studia Logica, Studia Logica, Vol. 85, No. 2 (2007), pp. 217$25 \mathrm{I}$

[28] Voutsadakis, G., Categorical Abstract Algebraic Logic: More on Protoalgebraicity, Notre Dame Journal of Formal Logic, Vol. 47, No. 4 (2006), pp. 487$5 \mathrm{I} 4$

[29] Voutsadakis, G., categorical Abstract Algebraic Logic: Protoalgebraicity and Leibniz Theory Systems, Scientiae Mathematicae Japonicae, Vol. 62, No. I (2005), pp. I09-II7

[30] Voutsadakis, G., Categorical Abstract Algebraic Logic: The Largest Theory System Included in a Theory Family, Mathematical Logic Quarterly, Vol. 52, No. 3 (2006), pp. 288-294

[3I] Voutsadakis, G., Categorical Abstract Algebraic Logic: Weakly Algebraizable $\pi$-Institutions, Submitted to the Archive for Mathematical Logic, Preprint available at http://www . voutsadakis . com/RESEARCH/papers .html

[32] Voutsadakis, G., Categorical Abstract Algebraic Logic: Strong Version of a Protoalgebraic $\pi$-Institution, Reports on Mathematical Logic, Vol. 42 (2007), pp. $19-46$ 
The Australasian fournal of Logic (ISSN I448-5052) disseminates articles that significantly advance the study of logic, in its mathematical, philosophical or computational guises. The scope of the journal includes all areas of logic, both pure and applied to topics in philosophy, mathematics, computation, linguistics and the other sciences.

Articles appearing in the journal have been carefully and critically refereed under the responsibility of members of the Editorial Board. Only papers judged to be both significant and excellent are accepted for publication.

The journal is freely available at the journal website at

$$
\text { http://www.philosophy.unimelb.edu.au/ajl/ }
$$

All issues of the journal are archived electronically at the journal website.

SuBSCRIPTIONS Individuals may subscribe to the journal by sending an email, including a full name, an institutional affiliation and an email address to the managing editor at ajl-editors@unimelb.edu.au Subscribers will receive email abstracts of accepted papers to an address of their choice. For institutional subscription, please email the managing editor at ajl-editors@unimelb.edu.au

Complete published papers may be downloaded at the journal's website at http: //www.philosophy.unimelb.edu.au/ajl/ The journal currently publishes in pdf format.

Submission The journal accepts submissions of papers electronically. To submit an article for publication, send the $\mathrm{LT}_{\mathrm{E}} \mathrm{X}$ source of a submission to a member of the editorial board. For a current list of the editorial board, consult the website.

The copyright of each article remains with the author or authors of that article. 